\title{
Molecular Mechanisms of TRPV1 Channel Activation
}

\author{
Andrés Jara-Oseguera ${ }^{1}$, Andrés Nieto-Posadas ${ }^{2}$, Arpad Szallasi ${ }^{3,4}$, León D. Islas ${ }^{1}$ and \\ Tamara Rosenbaum*2
}

\begin{abstract}
${ }^{I}$ Departamento de Fisiología, Facultad de Medicina, Universidad Nacional Autónoma de México, D.F. 04510 México; ${ }^{2}$ Departamento de Neurodesarrollo y Fisiología, División Neurociencias, Instituto de Fisiología, Celular, Universidad Nacional Autónoma de México, D.F. 04510, México; ${ }^{3}$ Department of Pathology, Monmouth Medical Center, Long Branch, NJ 07740, USA; ${ }^{4}$ Department of Pathology, Drexel University College of Medicine, Philadelphia, PA 19102, USA
\end{abstract}

\begin{abstract}
Transient Receptor Potential (TRP) cation channels participate in various fundamental processes in cell- and organism-physiology in unicellular eukaryotes, invertebrates and vertebrates. Interestingly, many TRP channels function as detectors of sensory stimuli. The TRPV1 (vanilloid 1) channel serves as an integrator of noxious chemical and physical stimuli known to cause irritation and pain, such as elevated temperatures, acids, and irritant chemical compounds, and its activation has been linked to acute nociceptive pain and neurogenic inflammation. The mechanisms by which the channel detects incoming stimuli, how the sensing domains are coupled to channel gating and how these processes are connected to specific structural regions in the channel are not fully understood, but valuable information is available. Many sites involved in agonist detection have been characterized and gating models that describe many features of the channel's behavior have been put forward. Structural and functional information indicates TRP channels are similar to voltage-activated potassium channels, with a tetrameric organization and six-transmembrane-region subunits, a pore domain with multi-ion binding properties and an intracellular S6 gate that seems to be the point of convergence of the many activation modalities leading to the opening of the ion conduction pathway. Furthermore, TRPV1 expression is altered in various disease states and TRPV1 gene polymorphism was speculated to play a role in pain sensation. The complex activation and regulation of TRPV1 may have important implications for drug development.
\end{abstract}

Keywords: Ion channels, activation gate, TRPV1, pain, capsaicin.

\section{INTRODUCTION}

The Transient Receptor Potential (TRP) family of ion channels comprises more than 30 members which are structurally related to voltage-activated channels. The first TRP channel was identified in a Drosophila melanogaster phototransduction mutant [1] which was known to be visually impaired [2], due to cells in the retina responding to light with a transient instead of a sustained electrical response. Since then, TRP channels have been identified in unicellular eukaryotes [3], invertebrates and vertebrates, including mammals and humans [4-8]. At least seven related TRP channel subfamilies have been described to date: TRPC (classical or canonical), TRPV (vanilloid), TRPM (melastatin), TRPA (ankyrin-like), TRPP (polycystin), TRPML (mucolipin) and TRPN (no mechanoreceptor potential C) [9-12].

TRP channels participate in several processes of paramount importance for the physiology of cells and organisms, including intracellular calcium homeostasis, cellular chemotaxis, neuronal guidance and neurite extension, epithelial electrolyte and calcium transport, cell proliferation and differentiation, the cellular immune response and several others [13-20]. Additionally, it is remarkable that many of these proteins are also involved in the detection of sensory stimuli of very different natures, including changes in osmolarity,

*Address correspondence to this author at the Departamento de Neurodesarrollo y Fisiología, División Neurociencias, Instituto de Fisiología Celular, Universidad Nacional Autónoma de México, D.F. 04510, México; Tel: +52 55562256 24; Fax: +52 55562256 07; E-mail: trosenba@ifc.unam.mx phototransduction, mechanical stimuli detection, taste- and pheromone recognition, thermosensation and painful and irritant stimuli detection [8].

The study of these channels has allowed us to establish specific links between everyday sensory stimuli and a discrete molecular entity. The TRPV1 (vanilloid 1) channel, which functions as an integrator of several stimuli known to cause pain and irritation, has been extensively studied. TRPV1 is predominantly expressed in primary sensory neurons with unmyelinated $\mathrm{C}$-fibers that have somata in dorsal root (DRG) and trigeminal ganglia (TG). The peripheral fibers of these neurons sense noxious stimuli (nociceptors) and are sites of release for pro-inflammatory neuropeptides that initiate the cascade of neurogenic inflammation. The central axons enter the central nervous system where they form synapses with second-order neurons in the dorsal horn of the spinal cord (DRG neurons) or the spinal nucleus of the trigeminal tract (TG neurons). A subset of DRG neurons with thin-myelinated (A $\delta)$-fibers also express TRPV1 [21-24]. Some nodose ganglion neurons projecting to the area postrema are likewise TRPV1-positive [25]. Albeit at much lower levels than in sensory neurons, TRPV1 expression has been described in various non-neuronal cells where its functions remain essentially unknown [26-32]. Interestingly, TRPV1 appears to be compartmentalized both at the anatomical (peripheral versus central receptors) and cellular (membrane-inserted versus subcellular organelles) levels [3335]. TRPV1 is the primary target of capsaicin, the irritant compound present in hot chili peppers [36], and is also acti- 
vated by several other molecules present in pungent food and spices, such as allicin and diallyl sulfides from garlic [3739], gingerol from ginger [40], alkylamides from Sichuan and Melegueta peppers [41] and piperine from black pepper [42], among several others. Other stimuli known to cause irritation such as extracellular acidification [43] and, interestingly, intracellular alkalinization [44], spider and jellyfish venom-derived toxins $[45,46]$ and elevated noxious temperatures above $42^{\circ} \mathrm{C}$ [36] also serve as channel agonists. Finally, TRPV1 is activated and modulated by transmembrane voltage [47-49] and several molecules such as lipids, vanilloid compounds like anandamide [50-56] and protein kinases [57-62] which exhibit activity linked to inflammatory processes. These molecules, together with protons and acidic signaling molecules like hydrogen sulfide [63], can be considered as endogenous TRPV1 ligands which regulate its activity according to the physiological state of the tissue it is expressed in. This behaviour places the TRPV1 channel at a very relevant position in the painand inflammatory signaling pathways. Its activation is one of the first molecular events leading to the perception of nociceptive pain and its function is finely tuned so that pain is only felt when a stimulus of particular intensity is applied, or when other sensitizing inputs, such as tissue damage or inflammation, are present. Furthermore, TRPV1 upregulation has been found to occur in various tissues under certain pathological conditions and diseases [64-75], and might underlie the exacerbated pain associated to these conditions. This makes TRPV1 a promising target for pain-relieving therapies and TRPV1 antagonists are currently undergoing clinical trials as novel analgesic drugs [76].

The polymodal nature of TRPV1 activation poses the following questions: 1) how does the protein manage to sense stimuli of such a diverse nature; 2) how do these stimuli finally translate into channel opening and 3) how does the protein integrate all the input signals it receives. We still have much to learn about how the activation pathways for several agonists are coupled to channel function and about the role of the different structural regions of TRPV1 in the activation by these agonists.

Despite the physiological importance of TRPV1 (and of TRP channels, in general), to date there is scarce structural information available on this protein. Nonetheless, valuable efforts have been made to establish mechanistic insights into the function of TRP channels at the molecular level. In the last few years, there have been efforts aimed at pinpointing the regions responsible for the specific action of agonists and their implications for a general gating scheme, the obtention of high resolution structures of specific TRP-channel domains and the identification of other structural components regulating the function of these proteins. In this review, we will survey some of the key findings concerning the molecular mechanisms underlying TRPV1 activation with stress on the contributions made by our research group.

\section{MECHANISMS OF AGONIST SENSING IN THE TRPV1: CAPSAICIN, VOLTAGE, TEMPERATURE AND LOW pH}

TRPV1 is a nonselective cation channel which is structurally related to the voltage-activated potassium $(\mathrm{Kv})$ channels. Biochemical assays and fluorescence and single chan- nel analysis indicate that the functional TRPV1 channel is a tetramer $[77,78]$. Hydropathy plots and sequence alignments suggest that each subunit is formed by six transmembrane segments (S1-6), with the $\mathrm{S} 5$, the $\mathrm{S} 6$ and the residues inbetween forming the pore of the channel, and with large intracellular amino $(\mathrm{N}-)$ and carboxi $(\mathrm{C})$ termini. A recently obtained tridimensional reconstruction of the channel at $19 \AA$ resolution by cryo-electronmycroscopy [79] indicated that it is similar, in terms of size and topology of both the transmembrane- and intracellular regions, to the mammalian Kv1.2 channel, whose structure has been determined at high resolution [80]. Similar studies with TRPM2 [81] and TRPC3 [82] suggest that these channels have more dilated intracellular structures as compared to Kv channels, and are more similar to the cystic fibrosis transmembrane regulator of conductance, CFTR [83]. In the case of TRPC3, these differences might arise from accessory subunits associated with the channel or from lipid aggregates included in the analysis [82, 84]. High-resolution X-ray diffraction data from several TRP channel domains such as the $\mathrm{N}$-terminal ankyrin repeat domains of rat TRPV1 $[85,86]$, rat [87] and human TRPV2 [88] and mouse TRPV6 [89] as well as the C-terminal coiled-coils [90] and atypical $\alpha$-kinase [91] from TRPM7 channels has also significantly contributed to our understanding of channel structure and function relationships. Aditionally, structure-function studies of the TRPV1 and related TRPV channels from several groups including our own [92-94] have confirmed that the S5-S6 region corresponds to the pore of the channel, with the lining of the inner pore formed by the alpha-helical S6 segments, and the residues between the S5 and S6 giving rise to the selectivity filter, the pore helix and the turret, similar to what has been observed in $\mathrm{Kv}$ channels. Fig. (1) displays a cartoon of a TRPV1 subunit with the approximate sites of action of several agonists and modulators, as well as some other structural features of the channel.

One of the better characterized agonists of the TRPV1 channel is capsaicin which, in fact, played a fundamental role in the identification and cloning of the receptor [36]. Capsaicin activates the channel with a $\mathrm{K}_{\mathrm{D}}$ (apparent dissociation constant) of around $300 \mathrm{nM}$ and a Hill coefficient of 2, indicating the presence of more than one capsaicin binding site in the channel, although the stochiometry of vanilloid binding has not been determined. This is in accord with the cooperative binding of the ultra potent TRPV1 agonist $\left[{ }^{3} \mathrm{H}\right]$ resiniferatoxin $\left(\left[{ }^{3} \mathrm{H}\right]-\mathrm{RTX}\right)$ binding to both native and cloned receptors [95-99]. Interestingly, single channel and binding studies indicate the presence of at least two binding sites, and show that partially bound channels are able to open with capsaicin binding preferentially to closed channels [99102]. Studies using chimeras between the capsaicin sensitive rat TRPV1 and the avian capsaicin-insensitive receptor have allowed identification of an intracellularly located capsaicin binding pocket in a region that spans from the S2 to the S4 of the channel [103]. Several other studies have refined the current model of the capsaicin binding site by combining mutagenesis with the use of capsaicin-related vanilloids such as RTX and its inactive iodinated form, iodo-resiniferatoxin (I-RTX), a competitive TRPV1 antagonist $[99,100]$. These studies have shown that, apparently, all vanilloids bind to the same region in the channel, albeit with some differences related to specific residue interactions with characteristic ago- 

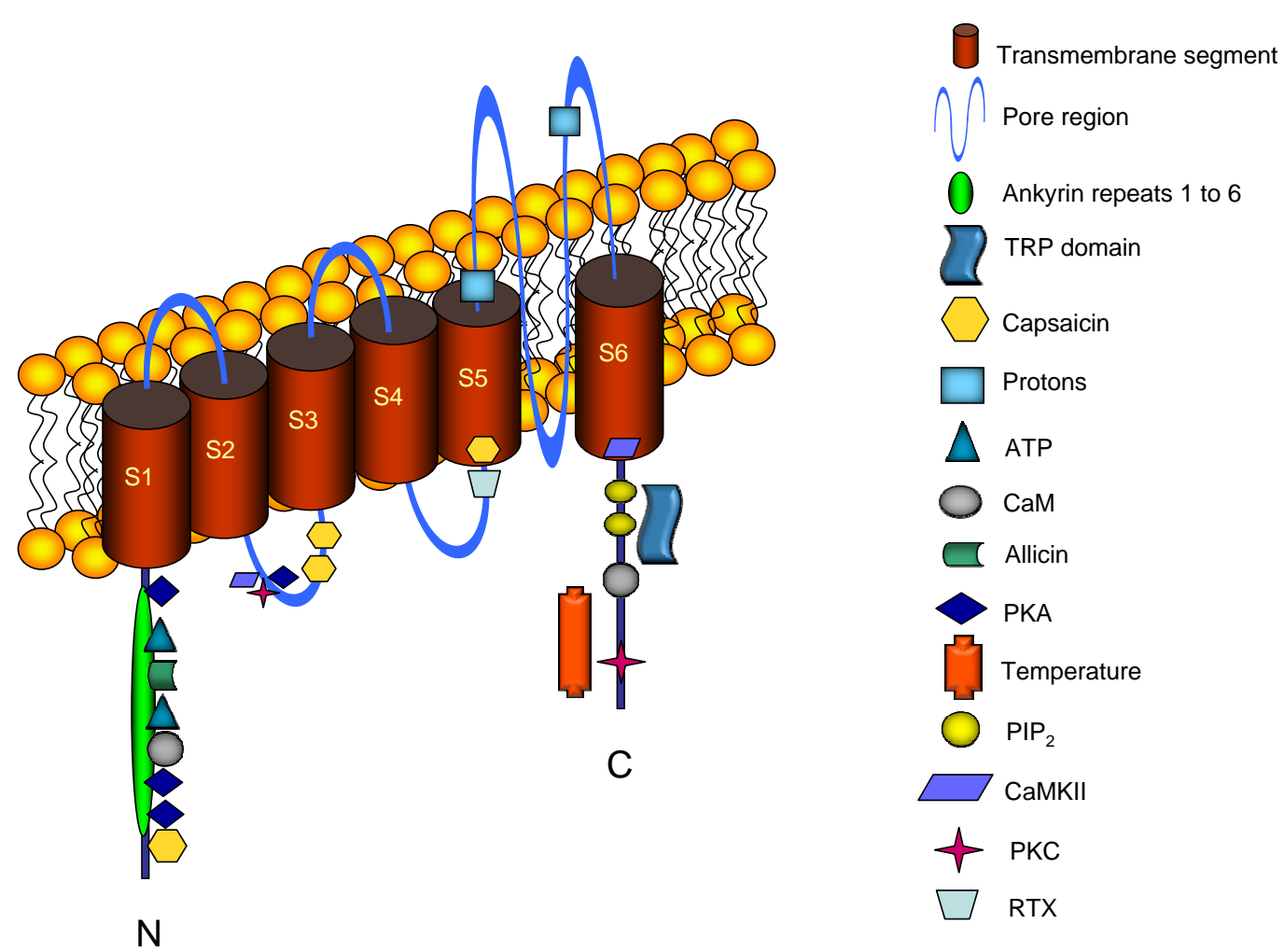

Fig. (1). Cartoon of a TRPV1 channel subunit with some key structural and regulatory sites. TRPV1 transmembrane segments S1-S6 are shown as red cylinders, with the amino- $(N)$ and carboxi- $(C)$ termini represented in dark blue. Some key structural features such as the six ankyrin repeats in the N-terminus and the sites of interaction of the receptor with several agonists or channel modulators are also displayed in their approximate positions along the subunit. Depicted agonists and modulators bind to: PKA to Ser 116, Thr 144 and Thr 370 , capsaicin to Arg 114, Tyr 511, Ser 512, Thr 550 and Glu 761, CaM to Lys 155, ATP to Lys 155, Lys 160 and Leu 163, allicin to Cys 157 , CaMKII to Ser 502 and Thr 704, RTX to Met 547, protons to Glu 600 and Glu 648, PIP 2 to Arg 701 and Lys 710 , PKC to Ser 502 and Ser 800, TRP domain comprising Glu 684 to Arg 721 and heat promotes its effects through interaction with the distal half of the C-terminus.

nist structural features. Additionally, several other residues spread over the entire protein such as the highly conserved TRP-box located near the pore [104, 105], the pore domain itself [106-108] and the N- and C-termini [48, 109] have been shown to affect the channel's response to capsaicin and even the binding of the vanilloid to its site.

In the TRPV1, there are conformational "waves" triggered by the association of one agonist in one region of the channel to other parts of the protein. An example of distinct activation pathways being propagated through different protein regions can be exemplified by the activation of the channel and the potentiation of its capsaicin response by low extracellular $\mathrm{pH}$. TRPV1 can be directly gated by low extracellular $\mathrm{pH}(<5.5)$, while higher but still acidic extracellular $\mathrm{pH}$ values $(\mathrm{pH} \sim 6.5)$ potentiate the channel's response to capsaicin without directly opening the ion conduction pathway [43]. These two processes were demonstrated to be mechanistically separate: two acidic residues located in the outer pore of the channel have been shown to be specific for either the agonist effect of protons (E648) or the low $\mathrm{pH}$ potentiation of the capsaicin response (E600) [110]. Residues located at the extracellular S3-S4 linker of TRPV1 appear to participate in the proton-mediated activation of the channel, without largely affecting other activation pathways [111]. Moreover, residue T633 located at the pore helix of the channel affects the direct agonist effect of protons when mutated to an alanine, leaving capsaicin and temperature activation and low $\mathrm{pH}$ potentiation of the receptor intact and suggesting that it is specifically involved in the coupling between the proton binding site at E648 and the opening of the gate [111]. Interestingly, mutation of the nearby residue F640 has profound effects on the receptor, facilitating capsaicin and temperature-activation of the channel, while the potentiation of the receptor by protons is lost [107]. These results suggest that the pore helix is important for the coupling between agonist binding and channel opening, and that different portions of the helix appear to transduce different signals to the gate domain. In these respect, mutations in five residues of the S6 segment of mouse and frog TRPV3 channel, which is activated by warm temperatures $\left(\sim 33{ }^{\circ} \mathrm{C}\right)$, abolish temperature activation without affecting channel activation by other agonists [112]. Finally, pharmacological evidence also points to the existence of structural regions specific for different TRPV1 agonists and activation mechanisms, since some receptor antagonists have been shown to inhibit both capsaicin- and proton-activation of the channel (class A), whereas others inhibit only the capsaicin-mediated activation (class B antagonists) [113, 114]. However, there seem to be differences in the effects of antagonists on the channel depending on the preparation employed [115] which may be due to tissue-specific post-translational modification, uncharacterized splice variants or other types of channel regulatory mechanisms. 
With regard to "long-distance" effects on the binding of an agonist, we must consider that since the binding of an agonist allosterically affects gating of the channel, mutations that affect the coupling between the binding of the agonist and the opening of the channel, might also lead to allosteric effects on the binding site, and hence on the site's affinity for the agonist. In fact, it has been observed that low $\mathrm{pH}$ positively affects capsaicin binding [116], and that low levels of I-RTX promote RTX binding [99]. Moreover, phosphorylation of the receptor by $\mathrm{Ca}^{2+}$ - calmodulin dependent kinase II (CaMKII) seems to regulate the activation/desensitization equilibrium of the channel by modulating the binding of capsaicin [61].

Voltage-activated $\mathrm{K}^{+}, \mathrm{Na}^{+}$and $\mathrm{Ca}^{2+}$ channels posses a voltage-sensing domain that allows them to transduce changes in transmembrane electric potential into protein conformational changes (Fig. 2). The voltage sensor in $\mathrm{Kv}$ channels is thought to be composed by the S4, which has a charged residue (Arg or Lys) for every third aminoacid in its sequence, so that the charges are able to sense and interact with the surrounding electric field (see [117-119] for review). Upon membrane depolarization, the S4 is thought to undergo some rotation and tilting (see [117, 120,121] for review). These changes are transduced to the pore domain via the S4-S5 linker and the C-terminal portion of the S6 [122-126], causing changes in the channel's open probability. Additionally, the S1-S3 segments can be said to contribute to voltage-sensing by influencing the electrostatic environment around the S4 [127-130]. Gating of TRP channels occurs similarly, with agonist sensing domains being coupled to the pore domain causing gating of the channel [12]. TRPV1 is also weakly gated by voltage [47-49], with a $V_{1 / 2}$ (half-activating voltage) of $150 \mathrm{mV}$ and a $\mathrm{z}$ (valence) of 0.5 at $17{ }^{\circ} \mathrm{C}$, and by temperature [36], with an activation threshold of $42{ }^{\circ} \mathrm{C}$ and a very high $\mathrm{Q}_{10}$ (temperature coefficient) > 20. The mechanisms leading to the high temperature sensitivity of the channel are not fully understood. Nilius and coworkers have suggested a simple two-state model for the heat-activated TRPV1 and the cold- and menthol- activated TRPM8 [49, 131]. In this model, movement of the voltage sensor is a requirement for channel activation. Temperature sensitivity arises from the fact that changes in entropy and enthalpy upon channel activation are large but comparable in size and independent of temperature, and that the voltagedependence of the channel is small, so that temperature changes cause large changes in the $\mathrm{V}_{1 / 2}$ of the channel, according the following equation: $V_{1 / 2}=\frac{\Delta H-T \Delta S}{z F}$, where $\Delta \mathrm{H}$ and $\Delta \mathrm{S}$ are the afore mentioned changes in enthalpy and entropy upon channel activation, $\mathrm{T}$ is the absolute temperature, $\mathrm{z}$ is the apparent valence of the opening transition and $\mathrm{F}$ is Faraday's constant. The difference between cold and heat activation is given by the opposing signs of $\Delta \mathrm{S}$ between TRPV1 and TRPM8, causing either a decrease or an increase in the $V_{1 / 2}$ upon heating, respectively. This two-state model was further extended for the TRPM8 [132] to include menthol binding. In that model, activation of the channel by temperature and voltage proceeded as before and menthol binding followed a Monod-Wyman-Changeaux (MWC) - type of behavior so that the channels could open in the absence of menthol, as has been observed for TRPV1 channels at depolarizing potentials at room temperature in the absence of capsaicin [133]. Moreover, residues in the putative S4 and S4-S5 linker of TRPM8 were shown to contribute to the gating charge of the channel (with apparent valence of 0.8 ) and to mediate the voltage sensitivity of the receptor, and hence, the temperature sensitivity [132].

Although the above model can account for several experimental observations, there are some results that seem to be at odds with a two-state model in which there are no independent voltage- and temperature- sensors. First, there are several single-channel studies that indicate that the channel gating scheme under activation with capsaicin, low $\mathrm{pH}$ or elevated temperature requires several open and closed states $[101,133,134]$. Second, a study in which the C-terminus modules of the TRPV1 and TRPM8 were swapped between each other to generate chimeric channels succeeded in generating a cold-activated TRPV1 and a heat-activated TRPM8 that continued to be activated by their canonical agonists, indicating that there seems to be a temperature-sensing module that operates independently from other agonist-sensing domains [135]. Additionally, the delay caused by the voltage-dependent transitions before channel opening, known as the Cole-Moore shift [136], seems to be independent from temperature in the TRPM8, a result that would not be expected if temperature- and voltage-activation of the channel occurred through the same mechanism [12]. Finally, it has been shown that neither capsaicin, temperature, voltage nor $\mathrm{pH}$ are full agonists of the TRPV1 channel, meaning that the maximal responses attainable under one of the activation pathways of the channel (e.g. by depolarizing voltages) is lower than the maximal response when the channel is challenged by two simultaneous stimuli. These findings have lead to the proposal of MWC-type of models for the TRPV1 [134] and TRPM8 [137] that consider voltage-, temperatureand ligand-activation of the channels to proceed through different modules that are allosterically coupled to the gate domain and to each other, similar to the model proposed for calcium- and voltage-activation of BK channels [138-140].

The MWC-type of model predicts several of the observations made for the TRPV1 channel, most of which come from macroscopic measurements. However, some of the results obtained from single channel analysis further complicate the panorama. Single channel analysis indicates that TRPV1 activity at low stimulation levels (capsaicin, $\mathrm{pH}$ or temperature) occurs in bursts separated by long gaps without openings $[101,116,141]$. Capsaicin, low $\mathrm{pH}$ or elevated temperature all seem to shorten the inter-burst closures, to elongate burst durations and to raise the overall open time per burst in a similar fashion, suggesting that the activation mechanisms by these stimuli are convergent. However, the presence of some intra-burst components and their time constants seem to be agonist-independent, although agonists might affect their relative occupancies [101, 116, 141]. These observations are not accounted for in any of the above-mentioned models, indicating that the gating scheme for the TRPV1 channels is far more complex.

\section{THE ROLE OF THE N-TERMINAL ANKYRIN RE- PEATS ON CHANNEL FUNCTION}

TRPV1 has large cytosolic $\mathrm{N}$ - and $\mathrm{C}$ termini. The $\mathrm{N}$ terminus has been shown to contain six ankyrin repeats 


\section{CLOSED}

\section{OPEN}

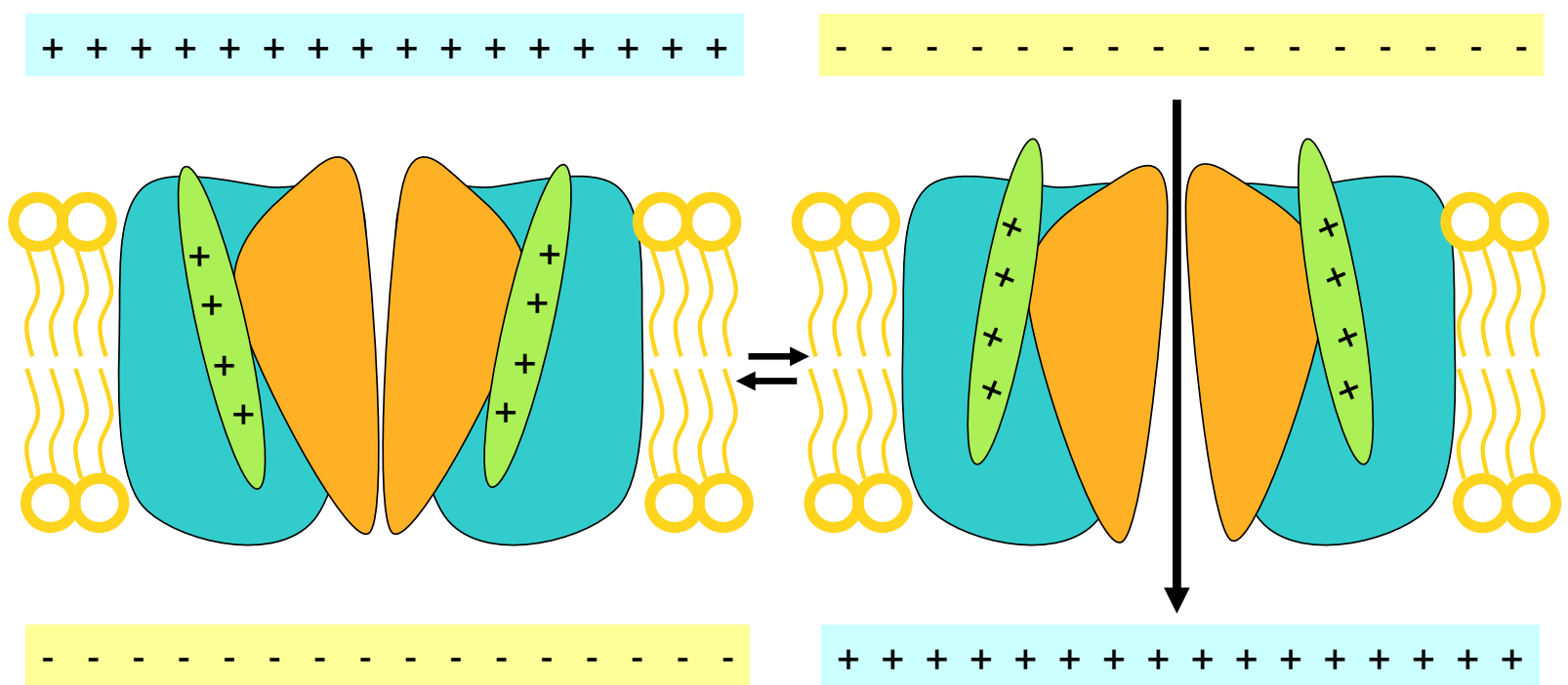

Fig. (2). Cartoon depicting voltage-activation of a voltage-activated channel. The pore domain is represented in orange, the S1-S4 in blue and the voltage-sensor (with positive charges) in green. The plus and minus signs represent membrane polarity. The voltage sensor is thought to undergo rotation and tilting with minor translation across the membrane. S4 conformational changes lead to gating of the pore via the S4S5 linker and the C-terminal portion of the S6.

(ANK), named after the cytoskeletal protein ankyrin, which contains 24 copies of these repeats [142]. ANK repeats have been implicated in a wide variety of processes such as protein-protein, protein-cytoskeleton and intersubunit interactions and multiligand binding, although their functions are not well understood.

Many members of the TRP family such as TRPA, TRPC, TRPN and TRPV have ANK repeats, the number of which varies from 3 to 29 [143]. The ankyrin repeats are formed by stretches of 33 amino acid residues that give rise to a structure consisting of a pair of anti-parallel $\alpha$-helices connected by a $\beta$-hairpin loop [144]. Some TRP ANK repeats are distinct from other ANK-repeat containing proteins, and even show significant differences among members of the TRP family. For example, both TRPA and TRPN channels posses a larger number of ankyrin repeat domains (ARD). The TRPV family has unique features as compared to the canonical ARD such as elongated finger loops, prominent twists amidst ankyrin repeats 1-4 and 5-6, which divide the ANK repeat domains of the channel in two regions, and aromatic residues present in a hydrophobic patch in the $\beta$-hairpin of ankyrin repeat 2 and 3 where proteins could perhaps interact [87-89].

TRP channels are thought to form homo- or heterotetrameric channels. Within the vanilloid family, it is known that the subunits preferentially form homotetrameric channels, with the exception of TRPV5 and TRPV6 which form heterotetramers with each other $[145,146]$. However, the molecular basis for TRP channel oligomerization had remained obscure until recently, when the C-termini or the ARD of the N-termini were implicated in the multimerization of members of the TRPV family [147-150]. Recent studies have identified protein motifs in the C-terminus of some voltage gated $\mathrm{K}^{+}$channels that act as an association domain (AD), named tetramerizing coiled coil (TCC). This domain can form $\alpha$-helical and coiled coil multimers, determining the stability and selectivity of multimerization [151-153].
Ferrer-Montiel and co-workers have proposed a molecular model of the C-terminus of TRPV1 where the TRP-like domain, an amphipatic $\alpha$-helix, acts as an AD that contributes to subunit oligomerization. They found that the C-termini associate in vitro, producing multimers, and that deletion of the $\mathrm{AD}$ results in monomers incapable of associating with each other, rendering the channels non-functional [147].

ANK repeats are extremely conserved between TRPV2 and TRPV1 and they do not act as multimerization domains, but rather as a site for interactions with regulatory molecules $[87,88]$. Nonetheless, the importance of ANK repeats in oligomerization of other members of the TRPV-channel family has been demonstrated some years ago by different research groups which have shown that, at least two regions in TRPV5, the N-terminus (aa 64-67) and the C-terminus (aa 596-601), are important in channel assembly, and that subunit association is critical in the routing and subsequent activity of the channel in the plasma membrane [148]. In a similar fashion, the third ANK repeat (aa 116-140) plays a critical role in subunit assembly of TRPV6, initiating a molecular zippering that proceeds past the fifth ANK repeat creating an intracellular anchor and which, if deleted or exchanged, makes the channel unable to self-associate [149]. Another study emphasized the relevance of ANK repeats in channel assembly for TRPV4, where splice variants of this channel which lacks these ANK domains displays impaired subunit assembly leading to retention of the protein in the endoplasmic reticulum [150].

Gaudet and collaborators have recently published the crystal structure of the TRPV1 ANK repeat-domain. As mentioned before, these domain exhibits great similarity with that of the TRPV2 channel, with some differences in the isoelectric point of the protein segment, with 8.3 for TRPV1 and 5.8 for TRPV2, indicating a more positively charged TRPV1 ARD which may, in fact, account for the differences in biological behavior. This research group also 
confirmed that the 1-3 ARD of TRPV1 are the locus for the ATP (adenosine triphosphate) binding site, which sensitizes the channel to activation by capsaicin. The triphosphate moiety of ATP interacts with the positively charged R115 of inner helix 1, K155 and K160 of the inner helix 2, while the adenine moiety interacts with L163 and Y199 of the inner helix 2 and finger 2, respectively, and with Q202 of finger 2 and E210 at the inner helix 3 [154].

Another interesting regulator of TRPV1 channel-activity is $\mathrm{Ca}^{2+}$-calmodulin $(\mathrm{CaM})$, which is known to promote desensitization of the channel in an intracellular $\mathrm{Ca}^{2+}$ dependent fashion. The mechanism involves a reduction of the macroscopic TRPV1 current by reducing the channel's open probability. The CaM binding site was localized to residues 189-222 of the N-terminus [155] (Fig. 1). The role of CaM in regulating TRPV1 activity is supported by another study which found that CaM binds to the ARD in a region which partially overlaps with the ATP-binding region [154]. Moreover, the obtained results suggest that upon channel activation, divalent cations such as $\mathrm{Ca}^{2+}$ and $\mathrm{Mg}^{2+}$ release and chelate ATP allowing the binding site to become accessible for CaM [154].

Phosphorylation also plays an important role in channel activity. Inflammatory mediators such as prostaglandins promote the activation of a PKA-dependent pathway influencing capsaicin- or heat-mediated actions of TRPV1 in sensory neurons. S116, located at the inner helix 1 of ARD, and T370, located after the ARD are phosphorylated by PKA and implicated in desensitization $[57,58]$. It has been proposed that phosphorylation introduces negative charges on S116 which in turn may interfere with the negatively charged CaM [154], while phosphorylation of the residues T144, T370 and S502 plays a role in the sensitization of heat-evoked currents [59].

It has been demonstrated that TRPV1 and TRPA1 can be activated by pungent compounds which modify cysteines in the N-terminus [37, 38, 156]. Using a combination of electrophysiological and behavioral assays in wild-type (WT), TRPV1- and TRPA1-null mice our group found that TRPV1 mediates part of the animal's response to allicin, and that this response is of physiological significance and clearly indicates that TRPV1 contributes to the perception of pain induced by allicin. Moreover, in the same study it was determined that a single cysteine residue at position 157 at the inner helix 2 of the second ankyrin repeat of the N-terminus was responsible for the actions of allicin. Mutation of C157 rendered the channel insensitive to cysteine modifying agents, and reinsertion of the cysteine into a cysteineless TRPV1 recovered the channel's response to allicin and other cysteine-derivatizing compounds [38]. C157 is localized close to the ATP binding pocket, which further stresses the importance of this region in the regulation of channel activity. In contrast, TRPA1 needs a cluster of three cysteines (C619, C639 and C663) to be activated by cysteinemodifying agents such as cinnamaldehyde and mustard oil [156]. Interestingly, TRPV1 is insensitive to some cysteinereactive species that activate the TRPA1, such as cinnamaldehyde and mustard oil, indicating that the binding site at C157 has a certain degree of selectivity [38]. Garlic diallyl sulfides also activate TRPA1 and TRPV1 channels [39], probably through a mechanism similar to the one mentioned above.
TRPA1 and TRPV1 can be activated in response to cellsurface tension changes [157-159]. The ankyrin domains in TRPA1 have been implicated in this mechanosensing response $[157,160]$. TRPV1 has been shown to respond to changes in osmolarity $[158,161-163]$, both to a hypertonic medium [158, 162] and to hypotonic buffers [158, 159]. Moreover, a TRPV1 N-terminal splice variant, characterized by the deletion of a stretch of amino acids from the $\mathrm{N}$ terminus, is required for osmosensitivity, wild-type neurons expressing this variant respond to hypertonic medium whereas neurons from TRPV1 knockout mice could not respond [161].

Membrane lipids play a critical role in the regulation of many functions of the cell, among them the regulation of ion channels. In the past few years, there has been an increasing interest on the regulation of TRPV1 by phospatidylinositol4,5-bisphosphate $\left(\mathrm{PIP}_{2}\right)$. It is known that $\mathrm{PIP}_{2}$ binds to the $\mathrm{C}$ terminus $[53,164]$, and it has been recently suggested that it could also bind to the N-terminus of the channel [154]. There has also been controversy regarding the effects of $\mathrm{PIP}_{2}$ on TRPV1, on whether it increases or decreases channel activity. The first reports suggested that the channel is inhibited by $\mathrm{PIP}_{2}$ and the relief from inhibition could be obtained by activation of PLC (phospholipase $\mathrm{C}$ ) and the resulting depletion of $\mathrm{PIP}_{2}$ [50]. This idea was based on indirect experiments where the effects of phosphoinositides were not directly tested in excised patches. When tested in excised patches it was found that $\mathrm{PIP}_{2}$ activates TRPV1 $[165,166]$. It is also known that desensitization, the loss of activity of the channel, occurs after prolonged capsaicin application. In this context Rohacs and colleagues have found that $\mathrm{Ca}^{2+}$ influx activates PLC which depletes $\mathrm{PIP}_{2}$ leading to desensitization. In addition, $\mathrm{PIP}_{2}$ had an inhibitory effect on the channel, but only at low capsaicin concentrations [167]. Qin and colleagues have shown that the recovery from desensitization occurs with high concentrations of ATP and resynthesis of $\mathrm{PIP}_{2}$ [52]. The overall evidence points to a role of ATP and $\mathrm{PIP}_{2}$ on sensitization of the channel. However, the role of the interaction of $\mathrm{PIP}_{2}$ with the $\mathrm{N}$-terminus has not yet been fully demonstrated.

\section{THE PORE AND THE ACTIVATION GATE OF THE TRPV1 CHANNEL}

The pore domain of $\mathrm{Kv}$ channels, as exemplified by the Kv1.2 structure, has been shown to be formed by the alphahelical S6 segments, which contribute to the lining of the inner pore, the turret, the p-loop, the pore helix and the S5 segment $[80,168]$. Each of the regions contributing to the pore domain has been found to serve specific functions. For example, the S6 segment contributes to the lining of the pore and constitutes the activation gate in Kv channels [169-171], opening and closing the ion conduction pathway in response to changes in transmembrane voltage, due to the coupling to the S4 voltage-sensing domain [122-126]. The pore helix and the selectivity filter, on the other hand, can undergo conformational changes that can also lead to a non-conducting state of the channel, however different from the closed state reached by the deactivation of the S6-gate [172]. It has also been found that selectivity in potassium channels can be altered by only substituting potassium ions by sodium [173], indicating that the selectivity filter is a dynamic structure. Moreover, in cyclic nucleotide-gated channels (CNG) the 
activation gate was found to lie in the selectivity filter [174], although the S6 still changes its conformation during gating transitions $[175,176]$. As can be seen, the pore domain is a dynamic structure that lies in the point of convergence of the different activation pathways a channel follows after an activating stimulus has been delivered, and is also subject to extensive regulation. Although we still do not have a high resolution structure of the pore of any TRP channel, important advances have been made in the study of the function and structure of the pore domain of these channels, which have demonstrated that they retain, in general terms, most of the structural and functional properties of voltage-activated $\mathrm{K}^{+}$channels.

For example, sequence alignments between $\mathrm{Kv}$ channels and TRPV1 indicate that the signature sequence for the $\mathrm{Kv}$ channel selectivity filter is likely to be conserved (to some degree) in the TRPV1 channel, whose sequence TIGMG aligns with TVGYG found in potassium channels [94]. Substitution of the methionine at the putative selectivity filter by a tyrosine does not significantly alter the selectivity of the channel [92]. This agrees with the results obtained from $\mathrm{Kv}$ channels, which allow substitutions in the tyrosine at the signature sequence to be made without altering the selectivity of the protein [177]. However, substitutions of other residues in the putative p-loop of the TRPV1 do change the pore properties of the channel. For example, neutralization of the acidic residue E646, which is presumably located at the extracellular pore entrance [178], reduces the sensitivity of the receptor to ruthenium red, a TRPV1 extracellular pore blocker, and also reduces the channel's permeability for magnesium relative to sodium [92]. Furthermore, neutralization of E636, which is expected to lie in the pore helix, also reduces the channel's permeability to calcium dramatically [106], and when substituted by a positive residue, renders the channel non-functional [92]. Nonetheless, the functionality can be rescued by substituting the lysine at position 639 by an acidic residue, indicating that these two residues are forming a salt bridge, something that would be expected if both were lying on an alpha-helix, i.e. the pore helix [92]. Moreover, residues D646 and E636 were recently found to be responsible for the proton-mediated decrease in single channel conductance. The mechanism of inhibition does neither involve competition between protons and permeant ions nor surface charge screening, but seems to be an allosteric process in which D646, E636 and K639 interact with each other through hydrogen bonding [179]. Studies conducted with other TRP channels have further confirmed the topology of the pore suggested here: D542 and D541 in the S5-S6 loop of TRPV5 and TRPV6, respectively, were found to underlie the high calcium permeability of these ion channels and to control the diameter of the pore $[180,181]$. The lack of an acidic residue at that position in TRPV1-4 seems to underlie the lower selectivity of these channels for calcium and divalent cations. Similar observations have been made with the calcium impermeable TRPM4 channel, in which mutations in the putative selectivity filter enabled calcium permeation through the receptor [182]. The outer pores of the TRPV6 and TRPV5 have been probed by using the substituted cysteine accessibility method (SCAM), and the results are also consistent with a pore topology similar to Kv channels [181, $183,184]$, albeit with differences regarding the size of the pore and the nature of the selectivity filter. Interestingly, a recent study suggests that the TRPV1 exhibits a phenomenon previously observed in P2X receptors $[185,186]$ called pore dilation, in which the channel's selectivity for large cations is increased as compared to sodium ions in an agonist exposure-time- and concentration-dependent manner [187]. However, single channel or cysteine-accessibility studies are required to clarify the nature of these observations.

The outer pore is the locus where several TRPV1 channel agonists bind, apart from protons: extracellular monovalent-, divalent- and trivalent- cations and polyamines [188-190] activate the channel through the same acidic residues as protons do. Notably, they have also been shown to affect other biophysical properties of the channel besides acting as channel agonists: protons reduce single channel current through the receptor $[116,179,191]$ and gadolinium even blocks the channel when present at high concentrations [189]. Moreover, calcium permeability seems to vary upon the nature of the agonist delivered, since its permeability coefficient with respect to monovalent ions has been shown to be reduced during proton-mediated gating as compared to when the channel is opened by capsaicin at neutral pH [192]. Furthermore, this phenomenon was found to depend on three acidic residues in the outer pore of the channel.

By performing a SCAM analysis of the outer pore of the TRPV5 and comparing residue modification before and after channel deactivation by intracellular acidification [193], it was found that the pore helix rotates in a clockwise direction to induce channel deactivation. It is evident that the pore helix seems to have a relevant role in transducing information from the different sensors of the channel to the opening of the pore, as has been further evidenced for the coupling between proton binding to E648 and the activation of the TRPV1 channel, which requires specific residues in the pore helix [111]. Other mutations in that region have been found to alter not only proton sensitivity, but also capsaicin and temperature sensitivity of the receptor [107], indicating that this region is very important for the gating activity of the channel.

By using quaternary ammonium blockers, a group of cationic pore blockers that have been extensively used to probe the pore of $\mathrm{Kv}$ channels [194-196], and that actually permitted the experimental identification of an activation gate for the first time in these channels, it was demonstrated that the TRPV1 channel actually has an intracellular gate that hinders the entrance to the pore of molecules at least the size of tetrapropylammonium (TPrA, $9 \AA$ ) $[133,197]$. Blocker molecules were found to block the channel in a voltagedependent manner, and to have blocking properties that were related to the presence of several ion-binding sites in the channel's selectivity filter, as observed in $\mathrm{K}^{+}$channels. Quaternary ammoniums lengthened the opening bursts of the channel at low capsaicin concentrations and slowed the deactivation kinetics at saturating agonist concentrations, reflected by slower tail currents, confirming that these molecules do indeed interfere with the closing of an intracellular gate of the channel. Interestingly, tetraethylammonium (TEA, $8 \AA$ ) did not apparently interfere with channel closure, indicating that it either is a state-independent blocker or that it can become trapped inside the channel pore. But do these findings imply that the TRPV1 channel possesses an intracellular activation gate similar to $\mathrm{Kv}$ channels? A study 
based on an alanine scan of the S6 had suggested that the segment was an alpha-helix. By using molecular dynamics simulations the authors hinted to the presence of two intracellular flexible points in the helix that might therefore change their conformation upon agonist delivery and gate the channel [198]. However, no experimental demonstration of an activation gate for the TRPV1 channel could be advanced.

Very recently our group performed a SCAM analysis of the S6, in which the state-dependence of accessibility of cysteine residues introduced along the S6 segment to cysteine modifiers of different sizes (MTSET, 5.8 A; MTSEA, $3.6 \AA$ and silver $-\mathrm{Ag}^{+}-1.26 \AA$ ) was evaluated [94]. The study succeeded in identifying two intracellular constrictions that constituted barriers to the permeation of ions, one located at the most intracellular region of the S6, at L681, and the other at the middle of the S6, at Y671. The most intracellular constriction at L681 was found to hamper the access of large cations, such as MTSET, to the inner pore of the channel, while allowing smaller cations such as silver and probably MTSEA to reach some upper positions in the S6. The second constriction at Y671 closed the ion conduction pathway even for silver, which is comparable in size to other permeating ions such as sodium (0.94 $\AA$ ) and potassium (1.33 $\AA$ ) (Fig. 3). This observation indicates that the constriction at Y 671 is the activation gate of the TRPV1 channel which opens and closes the ion conduction pathway upon capsaicin binding. Moreover, the proximity between the residues of the four S6 helices at both constrictions was confirmed by observing highly open state-dependent formation of disulfide bonds between cysteines introduced at either one of the two positions in a cysteineless background.

Regardless of the type of activating stimulus delivered to the channel, it might be expected, as said before, that the different pathways of channel activation converge in the opening of the gate. If this were the case, it would be expected that the same state-dependence observed when the channel is gated by capsaicin would be observed when the channel is activated by another stimulus. Indeed it was found

(a)

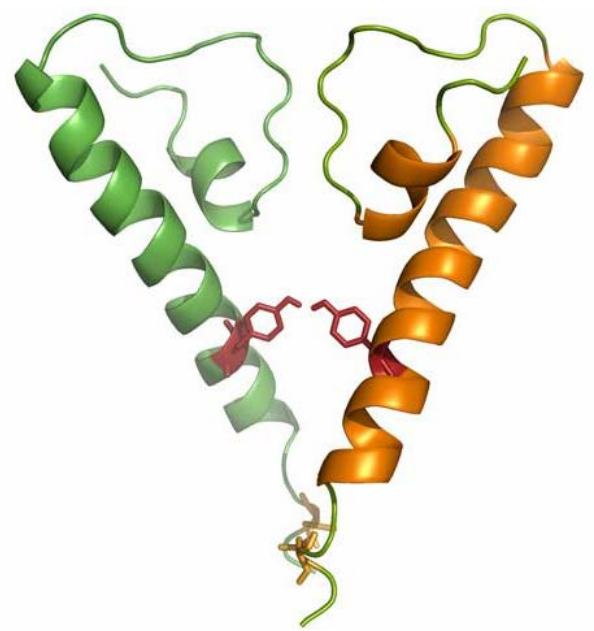

that the observations with capsaicin were reproduced when the channel was activated by elevated temperature, confirming that at least capsaicin and temperature activation converge in the opening of a single intracellular activation gate [94].

The constriction in those studies where we used quaternary ammoniums was the one located at L681, since it hampers the passage of ions larger than MTSET, including TEA and the larger QAs. We also conclude that a TEA molecule can become trapped inside the closed TRPV1 channel, so that the intracellular cavity of the channel should be able to accommodate a molecule at least the size of TEA.

Finally, harmonic analysis based on a discrete Fourier transform [199] of the rates of modification of the cysteines introduced along the $\mathrm{S} 6$ in the open state revealed a marked periodicity in the accessibility data that has a peak at $107^{\circ}$, which is expected for an alpha helix that is half exposed to an aqueous environment (the inner pore) and half exposed to an hydrophobic environment (the lipid bilayer and the rest of the protein), with fast modification occurring for the residues facing the pore, and slow modification observed for the residues facing the hydrophobic environment.

Quantification of an alpha-periodicity index for the data [200] further confirms that the S6 is an alpha helix, with the three last residues, including L681, lying in a protein loop that is no longer part of the helix [94]. Homology modeling allowed us to propose a model of the TRPV1 pore, in which both Y671 and L681 are facing the lumen of the pore (Fig. 3). Accordingly, a study has reported that mutation Y671K alters the channel's $\mathrm{Ca}^{2+}$ permeability and desensitization, as if the desensitized channel was destabilized by the mutation, and hence had been predicted to be contributing to the lining of the inner pore [201].

\section{TRPVI GENE POLYMORPHISM AND CHANNEL ACTIVATION}

The human TRPVI gene was mapped to chromosome 17 p13 [202]. The TRPV1 gene contains 18 exons and spans

\section{(b)}

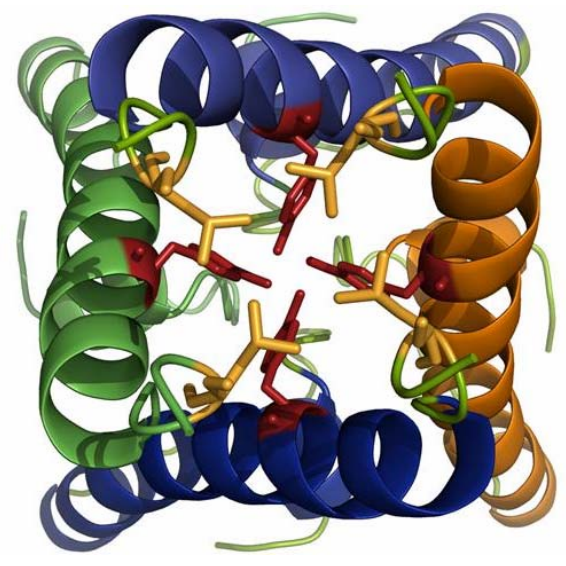

Fig. (3). TRPV1 homology model based on the Kv1.2 channel. (a) two segments of S6 with residues L681 (depicted in yellow) which obstruct the ion conduction pathway for large molecules and Y671 (depicted in red) which obstruct the ion conduction pathway for small permeating molecules, and constitutes the activation gate, (b) bottom view of the helical S6 transmembrane segments with residues L681 and Y671. 
at least $32 \mathrm{~kb}$. In the TRPV1 gene, frequent single nucleotide polymorphisms (SNPs) have been reported [203]. TRPV1 polymorphism has been linked to sensitivity to painful stimuli including noxious temperature and inflammation. For example, several SNP markers (including rs222747 and rs8065080, which induce amino acid changes of methionine to isoleucine at codon 315 and isoleucine to valine at codon 585 , respectively) have been linked to temperature-induced pain [204]. It was speculated that SNPs may form the molecular basis for gender-related differences in heat pain [204]. Nonetheless, to date no clear association between TRPV1 polymorphism and pain sensitivity has been reported.

Little is known about the influence of SNPs on TRPV1 channel activation. Six non-synonymous SNPs were reported to display similar $\mathrm{EC}_{50}$ values for capsaicin activation [203]. This is surprising since the oral burn produced by chili peppers shows striking interindividual differences. Interestingly, two TRPV1 SNPs (rs222749 and rs222747) when transfected into HEK293 cells showed enhanced responsiveness to anandamide, a putative endogenous TRPV1 agonist ("endovanilloid") [203]. Activation of TRPV1 by anandamide was postulated to play a role in the development of hypertension [205-207]. If so, individuals with these TRPV1 SNPs may be prone to suffer from high blood pressure. It can be speculated that TRPV1 SNPs can also confer higher sensitivity to other agonists. Propofol, a known activator of TRPV1 [208], was reported to cause excruciating pain in some patients but not others [209-211].

\section{DISEASE-RELATED CHANGES IN THE EXPRES- SION OF TRPV1 AND RELATED CHANNELS RELE- VANT TO PAIN}

TRPV1 shows bi-directional changes, up- or downregulation, during disease states (see [212] for review). For example, during inflammation and in bone cancer TRPV1 levels increase substantially $[64,213,214]$. Conversely, TRPV1 expression is down-regulated in neuropathic pain secondary to injury $[215,216]$. In a rodent model of diabetic neuropathy, the early hyperalgesic state has been linked to increased TRPV1 expression whereas the late hypoalgesic state was accompanied by a virtual absence of TRPV1 receptors [217]. In accord, in the skin of patients with diabetic neuropathy, TRPV1-expressing epidermal nerve fibers are markedly reduced [75]. It has been hypothesized that the down-regulation of TRPV1 expression in diabetic skin is related to the diminished nerve growth factor (NGF) levels [75]. By this reasoning, increased TRPV1 levels during inflammation can be attributed to enhanced NGF production. Indeed, capsaicin-sensitivity of DRG neurons is regulated by NGF in vitro [218, 219]. Capsaicin was reported to interfere with the centripetal intraaxonal transport of NGF from the periphery to the perikarya of TRPV1-expressing neurons and this effect was surmised to contribute to capsaicin-induced desensitization [220].

Painful human disease states with enhanced TRPV1 expression include inflammatory bowel disease (both Crohn's disease and ulcerative colitis) [68], fecal urgency/irritable bowel syndrome [221, 222], reflux esophagitis [223], vulvar allodynia [66], and pain (mastopathy) secondary to macromastia [69]. As discussed above, low $\mathrm{pH}$ is capable of activating TRPV1 directly [43]. Thus, it is easy to visualize the link between increased TRPV1 expression, "heart-burn" and regurgirated gastric acid in patients with reflux esophagitis. It is a common observation that alcohol consumption often causes a burning sensation in reflux esophagitis patients. Indeed, ethanol was reported to potentiate the activation of TRPV1 by its agonists including heat and protons [224, 225]. Less clear is the activation mechanism of TRPV 1 in patients with inflammatory bowel disease or fecal urgency, where channel activation by hydrogen sulfide may play a role [226, 227].

A well-defined subpopulation of chronic cough patients is distinguised by their unique sensitivity to capsaicinevoked cough. These patients have increased TRPV1 receptors levels in their airways [70, 72]. Apparently, there is a significant overlap between patients with chronic cough and sensory hypersensitivity but not asthma (see [228-230] for review). Since many patients with reflux esophagitis also suffer from chronic cough (especially in the morning) (see [231] for review), it is a reasonable assumption that the cough reflex in these patients is driven by inhaled acid acting on airway TRPV1 receptors [232].

Although strictly speaking not a disease, it should be mentioned that chronic morphine administration up-regulates TRPV1 expression in the spinal cord in a MAP kinasedependent manner [233]. This is intriguing because morphine tolerance is often associated with the development of thermal hyperalgesia [234-237]. In fact, intrathecal pretreatment with the TRPV1 antagonist SB366791 [N-(3methoxyphenyl)-4-chlorocinnamide] has been shown to attenuate morphine tolerance and to prevent thermal hyperalgesia [233]. It is hoped that TRPV1 antagonists will reduce the need for opioids and, as an added benefit, also prevent tolerance to opioids. Interestingly, acute morphine administration has the opposite effect, since it negatively modulates TRPV1 via inhibition of adenylate cyclase [238, 239].

This bi-directional regulation of expression during disease states is, however, not specific to TRPV1. For example, TRPV4 has been linked to chemotherapy (e.g. taxol- or vincristine)-induced neuropathy [240]. In accord, TRPV4 antisense oligodeoxynucleotide given intrathecally reverses mechanical allodynia and ameliorates mechanical hyperalgesia in animal models of neuropathy of various etiologies, such as diabetes, alcoholism, and chemotherapy [241]. Another example of this phenomenon is TRPM8. In rat DRG, mRNA encoding TRPM8 is increased following chronic constriction injury [242]. However, in human TRPM8 appears to be conversely down-regulated in painful dental pulp [243]. Indeed, no evidence for the involvement of TRPM8 in cold allodynia has been found in neuropathic pain patients [244]. This is a worrisome example of the species-related differences in TRP channel biology that hinder extrapolation of animal experiments to patients.

\section{ACKNOWLEDGEMENTS}

This work was supported by grants from DGAPAUNAM IN200308-3 and CONACyT No. 58038 to T.R.

\section{REFERENCES}

[1] Montell C, Rubin GM. Molecular characterization of the Drosophila trp locus: a putative integral membrane protein required for phototransduction. Neuron 1989; 2: 1313-23. 
[2] Cosens DJ, Manning A. Abnormal electroretinogram from a Drosophila mutant. Nature $1969 ; 224: 285-7$.

[3] Palmer CP, Zhou XL, Lin J, et al. A TRP homolog in Saccharomyces cerevisiae forms an intracellular $\mathrm{Ca}(2+)$-permeable channel in the yeast vacuolar membrane. Proc Natl Acad Sci USA 2001; 98: 7801-5.

[4] Montell C, Birnbaumer L, Flockerzi V. The TRP channels, a remarkably functional family. Cell 2002; 108: 595-8.

[5] Montell C. The TRP superfamily of cation channels. Sci STKE 2005; 2005: re3.

[6] Nilius B, Voets T. TRP channels: a TR(I)P through a world of multifunctional cation channels. Pflugers Arch 2005; 451: 1-10.

[7] Ramsey IS, Delling M, Clapham DE. An introduction to TRP channels. Annu Rev Physiol 2006; 68: 619-47.

[8] Damann N, Voets T, Nilius B. TRPs in our senses. Curr Biol 2008; 18: R880-9.

[9] Clapham DE, Runnels LW, Strubing C. The TRP ion channel family. Nat Rev Neurosci 2001; 2: 387-96.

[10] Montell C, Birnbaumer L, Flockerzi V, et al. A unified nomenclature for the superfamily of TRP cation channels. Mol Cell 2002; 9: 229-31.

[11] Moran MM, Xu H, Clapham DE. TRP ion channels in the nervous system. Curr Opin Neurobiol 2004; 14: 362-9.

[12] Latorre R, Brauchi S, Orta G, Zaelzer C, Vargas G. ThermoTRP channels as modular proteins with allosteric gating. Cell Calcium 2007; 42: 427-38.

[13] Damann N, Owsianik G, Li S, Poll C, Nilius B. The calciumconducting ion channel transient receptor potential canonical 6 is involved in macrophage inflammatory protein-2-induced migration of mouse neutrophils. Acta Physiol (Oxf) 2009; 195: 3-11.

[14] Masuyama R, Vriens J, Voets T, et al. TRPV4-mediated calcium influx regulates terminal differentiation of osteoclasts. Cell Metab 2008; 8: 257-65.

[15] Abramowitz J, Birnbaumer L. Physiology and pathophysiology of canonical transient receptor potential channels. FASEB J 2009; 23: 297-328.

[16] Clapham DE. TRP channels as cellular sensors. Nature 2003; 426: 517-24.

[17] Kiselyov K, Patterson RL. The integrative function of TRPC channels. Front Biosci 2009; 14: 45-58.

[18] Talavera K, Nilius B, Voets T. Neuronal TRP channels: thermometers, pathfinders and life-savers. Trends Neurosci 2008; 31: 287-95.

[19] Liedtke W. Molecular mechanisms of TRPV4-mediated neural signaling. Ann N Y Acad Sci 2008; 1144: 42-52.

[20] Christensen AP, Corey DP. TRP channels in mechanosensation: direct or indirect activation? Nat Rev Neurosci 2007; 8: 510-21.

[21] Price TJ, Flores CM. Critical evaluation of the colocalization between calcitonin gene-related peptide, substance P, transient receptor potential vanilloid subfamily type 1 immunoreactivities, and isolectin B4 binding in primary afferent neurons of the rat and mouse. J Pain 2007; 8: 263-72.

[22] Szolcsanyi J. Capsaicin-sensitive sensory nerve terminals with local and systemic efferent functions: facts and scopes of an unorthodox neuroregulatory mechanism. Prog Brain Res 1996; 113: 343-59.

[23] Szallasi A, Blumberg PM. Characterization of vanilloid receptors in the dorsal horn of pig spinal cord. Brain Res 1991; 547: 335-8.

[24] Szallasi A, Nilsson S, Farkas-Szallasi T, et al. Vanilloid (capsaicin) receptors in the rat: distribution in the brain, regional differences in the spinal cord, axonal transport to the periphery, and depletion by systemic vanilloid treatment. Brain Res 1995; 703: 175-83.

[25] Patterson LM, Zheng H, Ward SM, Berthoud HR. Vanilloid receptor (VR1) expression in vagal afferent neurons innervating the gastrointestinal tract. Cell Tissue Res 2003; 311:277-87.

[26] Lundberg JM, Martling CR, Saria A. Substance P and capsaicininduced contraction of human bronchi. Acta Physiol Scand 1983; 119: 49-53.

[27] Siegmund SV, Uchinami H, Osawa Y, Brenner DA, Schwabe RF. Anandamide induces necrosis in primary hepatic stellate cells. Hepatology 2005; 41: 1085-95.

[28] Szallasi A, Conte B, Goso C, Blumberg PM, Manzini S. Characterization of a peripheral vanilloid (capsaicin) receptor in the urinary bladder of the rat. Life Sci 1993; 52: PL221-6.

[29] Biro T, Bodo E, Telek A, et al. Hair cycle control by vanilloid receptor-1 (TRPV1): evidence from TRPV1 knockout mice. J Invest Dermatol 2006; 126: 1909-12.
[30] Stander S, Moormann C, Schumacher M, et al. Expression of vanilloid receptor subtype 1 in cutaneous sensory nerve fibers, mast cells, and epithelial cells of appendage structures. Exp Dermatol 2004; 13: 129-39.

[31] Inoue K, Koizumi S, Fuziwara S, et al. Functional vanilloid receptors in cultured normal human epidermal keratinocytes. Biochem Biophys Res Commun 2002; 291: 124-9.

[32] Mezey E, Toth ZE, Cortright DN, et al. Distribution of mRNA for vanilloid receptor subtype 1 (VR1), and VR1-like immunoreactivity, in the central nervous system of the rat and human. Proc Natl Acad Sci USA 2000; 97: 3655-60.

[33] Liu M, Liu MC, Magoulas C, Priestley JV, Willmott NJ. Versatile regulation of cytosolic $\mathrm{Ca}^{2+}$ by vanilloid receptor $\mathrm{I}$ in rat dorsal root ganglion neurons. J Biol Chem 2003; 278: 5462-72.

[34] Marshall IC, Owen DE, Cripps TV, et al. Activation of vanilloid receptor 1 by resiniferatoxin mobilizes calcium from inositol 1,4,5trisphosphate-sensitive stores. Br J Pharmacol 2003; 138: 172-6.

[35] Turner H, Fleig A, Stokes A, Kinet JP, Penner R. Discrimination of intracellular calcium store subcompartments using TRPV1 (transient receptor potential channel, vanilloid subfamily member 1) release channel activity. Biochem J 2003; 371: 341-50.

[36] Caterina MJ, Schumacher MA, Tominaga M, et al. The capsaicin receptor: a heat-activated ion channel in the pain pathway. Nature 1997; 389: 816-24.

[37] Macpherson LJ, Geierstanger BH, Viswanath $\mathrm{V}$, et al. The pungency of garlic: activation of TRPA1 and TRPV1 in response to allicin. Curr Biol 2005; 15: 929-34.

[38] Salazar H, Llorente I, Jara-Oseguera A, et al. A single N-terminal cysteine in TRPV1 determines activation by pungent compounds from onion and garlic. Nat Neurosci 2008; 11: 255-61.

[39] Koizumi K, Iwasaki Y, Narukawa M, et al. Diallyl sulfides in garlic activate both TRPA1 and TRPV1. Biochem Biophys Res Commun 2009; 382: 545-8.

[40] Iwasaki Y, Morita A, Iwasawa T, et al. A nonpungent component of steamed ginger--[10]-shogaol--increases adrenaline secretion via the activation of TRPV1. Nutr Neurosci 2006; 9: 169-78.

[41] Riera C, Menozzi-Smarrito C, Affolter M, et al. Compounds from Sichuan and Melegueta peppers activate, covalently and noncovalently, TRPA1 and TRPV1 channels. Br J Pharmacol 2009; 157(8): 1398-409.

[42] McNamara FN, Randall A, Gunthorpe MJ. Effects of piperine, the pungent component of black pepper, at the human vanilloid receptor (TRPV1). Br J Pharmacol 2005; 144: 781-90.

[43] Tominaga M, Caterina MJ, Malmberg AB, et al. The cloned capsaicin receptor integrates multiple pain-producing stimuli. Neuron 1998; 21: 531-43.

[44] Dhaka A, Uzzell V, Dubin AE, et al. TRPV1 is activated by both acidic and basic pH. J Neurosci 2009; 29: 153-8.

[45] Cuypers E, Yanagihara A, Karlsson E, Tytgat J. Jellyfish and other cnidarian envenomations cause pain by affecting TRPV1 channels. FEBS Lett 2006; 580: 5728-32.

[46] Siemens J, Zhou S, Piskorowski R, et al. Spider toxins activate the capsaicin receptor to produce inflammatory pain. Nature 2006; 444: 208-12.

[47] Gunthorpe MJ, Harries MH, Prinjha RK, Davis JB, Randall A. Voltage- and time-dependent properties of the recombinant rat vanilloid receptor (rVR1). J Physiol 2000; 525 Pt 3: 747-59.

[48] Vlachova V, Teisinger J, Susankova K, et al. Functional role of Cterminal cytoplasmic tail of rat vanilloid receptor 1. J Neurosci 2003; 23: 1340-50.

[49] Voets T, Droogmans G, Wissenbach U, et al. The principle of temperature-dependent gating in cold- and heat-sensitive TRP channels. Nature 2004; 430: 748-54.

[50] Chuang HH, Prescott ED, Kong H, et al. Bradykinin and nerve growth factor release the capsaicin receptor from $\operatorname{Ptd} \operatorname{Ins}(4,5) \mathrm{P} 2$ mediated inhibition. Nature 2001; 411: 957-62.

[51] Hwang SW, Cho H, Kwak J, et al. Direct activation of capsaicin receptors by products of lipoxygenases: endogenous capsaicin-like substances. Proc Natl Acad Sci USA 2000; 97: 6155-60.

[52] Liu B, Zhang C, Qin F. Functional recovery from desensitization of vanilloid receptor TRPV1 requires resynthesis of phosphatidylinositol 4,5-bisphosphate. J Neurosci 2005; 25: 4835-43.

[53] Brauchi S, Orta G, Mascayano C, et al. Dissection of the components for PIP2 activation and thermosensation in TRP channels. Proc Natl Acad Sci USA 2007; 104: 10246-51. 
[54] Ahern GP. Activation of TRPV1 by the satiety factor oleoylethanolamide. J Biol Chem 2003; 278: 30429-34.

[55] Zygmunt PM, Petersson J, Andersson DA, et al. Vanilloid receptors on sensory nerves mediate the vasodilator action of anandamide. Nature 1999; 400: 452-7.

[56] Matta JA, Miyares RL, Ahern GP. TRPV1 is a novel target for omega-3 polyunsaturated fatty acids. J Physiol 2007; 578: 397-411.

[57] Mohapatra DP, Nau C. Desensitization of capsaicin-activated currents in the vanilloid receptor TRPV1 is decreased by the cyclic AMP-dependent protein kinase pathway. J Biol Chem 2003; 278: 50080-90.

[58] Bhave G, Zhu W, Wang $\mathrm{H}$, et al. cAmp-Dependent protien kinase regulates desensitization of the capsaicin receptor (VR1) by direct phosphorylation. Neuron 2002; 35: 721-31.

[59] Rathee P, Distler C, Obreja O, et al. PKA/AKAP/VR-1 module: A common link of Gs-mediated signaling to thermal hyperalgesia. J Neurosci 2002; 22: 4740-5.

[60] Bhave G, Hu HJ, Glauner KS, et al. Protein kinase C phosphorylation sensitizes but does not activate the capsaicin receptor transient receptor potential vanilloid 1 (TRPV1). Proc Natl Acad Sci USA 2003; 100: 12480-5

[61] Jung J, Shin JS, Lee SY, et al. Phosphorylation of vanilloid receptor 1 by $\mathrm{Ca} 2+$ /calmodulin-dependent kinase II regulates its vanilloid binding. J Biol Chem 2004; 279: 7048-54.

[62] Premkumar LS, Qi ZH, Van Buren J, Raisinghani M. Enhancement of potency and efficacy of NADA by PKC-mediated phosphorylation of vanilloid receptor. J Neurophysiol 2004; 91: 1442-9.

[63] Trevisani M, Patacchini R, Nicoletti $P$, et al. Hydrogen sulfide causes vanilloid receptor 1-mediated neurogenic inflammation in the airways. Br J Pharmacol 2005; 145: 1123-31.

[64] Niiyama Y, Kawamata T, Yamamoto J, Omote K, Namiki A. Bone cancer increases transient receptor potential vanilloid subfamily 1 expression within distinct subpopulations of dorsal root ganglion neurons. Neuroscience 2007; 148: 560-72.

[65] Lee LY, Gu Q. Role of TRPV1 in inflammation-induced airway hypersensitivity. Curr Opin Pharmacol 2009; 9: 243-9.

[66] Tympanidis P, Casula MA, Yiangou Y, et al. Increased vanilloid receptor VR1 innervation in vulvodynia. Eur J Pain 2004; 8: 12933.

[67] Birder LA. TRPs in bladder diseases. Biochim Biophys Acta 2007; 1772: 879-84.

[68] Yiangou Y, Facer P, Dyer NH, et al. Vanilloid receptor 1 immunoreactivity in inflamed human bowel. Lancet 2001; 357: 13389.

[69] Gopinath P, Wan E, Holdcroft A, et al. Increased capsaicin receptor TRPV1 in skin nerve fibres and related vanilloid receptors TRPV3 and TRPV4 in keratinocytes in human breast pain. BMC Womens Health 2005; 5: 2 .

[70] Groneberg DA, Niimi A, Dinh QT, et al. Increased expression of transient receptor potential vanilloid-1 in airway nerves of chronic cough. Am J Respir Crit Care Med 2004; 170: 1276-80.

[71] Zhang G, Lin RL, Wiggers M, Snow DM, Lee LY. Altered expression of TRPV1 and sensitivity to capsaicin in pulmonary myelinated afferents following chronic airway inflammation in the rat. $\mathrm{J}$ Physiol 2008; 586: 5771-86.

[72] Mitchell JE, Campbell AP, New NE, et al. Expression and characterization of the intracellular vanilloid receptor (TRPV1) in bronchi from patients with chronic cough. Exp Lung Res 2005; 31: 295306.

[73] Watanabe N, Horie S, Spina D, et al. Immunohistochemical localization of transient receptor potential vanilloid subtype 1 in the trachea of ovalbumin-sensitized Guinea pigs. Int Arch Allergy Immunol 2008; 146 (Suppl 1): 28-32.

[74] Hong S, Wiley JW. Early painful diabetic neuropathy is associated with differential changes in the expression and function of vanilloid receptor 1. J Biol Chem 2005; 280: 618-27.

[75] Facer P, Casula MA, Smith GD, et al. Differential expression of the capsaicin receptor TRPV1 and related novel receptors TRPV3, TRPV4 and TRPM8 in normal human tissues and changes in traumatic and diabetic neuropathy. BMC Neurol 2007; 7: 11.

[76] Patapoutian A, Tate S, Woolf CJ. Transient receptor potential channels: targeting pain at the source. Nat Rev Drug Discov 2009; 8: 55-68.

[77] Cheng W, Yang F, Takanishi CL, Zheng J. Thermosensitive TRPV channel subunits coassemble into heteromeric channels with inter- mediate conductance and gating properties. J Gen Physiol 2007; 129: 191-207.

[78] Kedei N, Szabo T, Lile JD, et al. Analysis of the native quaternary structure of vanilloid receptor 1. J Biol Chem 2001; 276: 28613-9.

[79] Moiseenkova-Bell VY, Stanciu LA, Serysheva, II, Tobe BJ, Wensel TG. Structure of TRPV1 channel revealed by electron cryomicroscopy. Proc Natl Acad Sci USA 2008; 105: 7451-5.

[80] Long SB, Campbell EB, Mackinnon R. Crystal structure of a mammalian voltage-dependent Shaker family $\mathrm{K}^{+}$channel. Science 2005; 309: 897-903

[81] Maruyama Y, Ogura T, Mio K, et al. Three-dimensional reconstruction using transmission electron microscopy reveals a swollen, bell-shaped structure of transient receptor potential melastatin type 2 cation channel. J Biol Chem 2007; 282: 36961-70.

[82] Mio K, Ogura T, Kiyonaka S, et al. The TRPC3 channel has a large internal chamber surrounded by signal sensing antennas. J Mol Biol 2007; 367: 373-83

[83] Mio K, Ogura T, Mio M, et al. Three-dimensional reconstruction of human cystic fibrosis transmembrane conductance regulator chloride channel revealed an ellipsoidal structure with orifices beneath the putative transmembrane domain. J Biol Chem 2008; 283: 30300-10.

[84] Moiseenkova-Bell VY, Wensel TG. Hot on the trail of TRP channel structure. J Gen Physiol 2009; 133: 239-44.

[85] Gaudet R. Divide and conquer: high resolution structural information on TRP channel fragments. J Gen Physiol 2009; 133: 231-7.

[86] Lishko PV, Procko E, Jin X, Phelps CB, Gaudet R. The ankyrin repeats of TRPV1 bind multiple ligands and modulate channel sensitivity. Neuron 2007; 54: 905-18.

[87] Jin X, Touhey J, Gaudet R. Structure of the N-terminal ankyrin repeat domain of the TRPV2 ion channel. J Biol Chem 2006; 281: 25006-10.

[88] Mccleverty C, Koesema E, Patapoutian A, Lesley S, Kreusch A. Crystal structure of the human TRPV2 channel ankyrin repeat domain. Prot Sci 2006; 2201-6.

[89] Phelps B, Huang R, Lishko P, Wang R, Gaudet R. Structural analyses of the ankyrin repeat domain of TRPV6 and related TRPV ion channels. Biochemistry 2008; 2476-84.

[90] Fujiwara Y, Minor DL, Jr. X-ray crystal structure of a TRPM assembly domain reveals an antiparallel four-stranded coiled-coil. J Mol Biol 2008; 383: 854-70.

[91] Yamaguchi H, Matsushita M, Nairn AC, Kuriyan J. Crystal structure of the atypical protein kinase domain of a TRP channel with phosphotransferase activity. Mol cell 2001; 7: 1047-57.

[92] Garcia-Martinez C, Morenilla-Palao C, Planells-Cases R, Merino JM, Ferrer-Montiel A. Identification of an aspartic residue in the Ploop of the vanilloid receptor that modulates pore properties. J Biol Chem 2000; 275: 32552-8.

[93] Owsianik G, Talavera K, Voets T, Nilius B. Permeation and selectivity of TRP channels. Annu Rev Physiol 2006; 68: 685-717.

[94] Salazar H, Jara-Oseguera A, Hernandez-Garcia E, et al. Structural determinants of gating in the TRPV1 channel. Nat Struct Mol Biol 2009; 16: 704-10.

[95] Acs G, Palkovits M, Blumberg PM. [3H]resiniferatoxin binding by the human vanilloid (capsaicin) receptor. Brain Res Mol Brain Res 1994; 23: 185-90.

[96] Acs G, Blumberg PM. [3H]resiniferatoxin binding to pig dorsal horn membranes displays positive cooperativity. Life Sci 1994; 55: $337-46$.

[97] Szallasi A, Goso C. Characterization by [3H]resiniferatoxin binding of a human vanilloid (capsaicin) receptor in post-mortem spinal cord. Neurosci Lett 1994; 165: 101-4.

[98] Szallasi A, Lewin NA, Blumberg PM. Vanilloid (capsaicin) receptor in the rat: positive cooperativity of resiniferatoxin binding and its modulation by reduction and oxidation. J Pharmacol Exp Ther 1993; 266: 678-83

[99] Chou MZ, Mtui T, Gao YD, Kohler M, Middleton RE. Resiniferatoxin binds to the capsaicin receptor (TRPV1) near the extracellular side of the S4 transmembrane domain. Biochemistry 2004; 43: 2501-11.

[100] Gavva NR, Klionsky L, Qu Y, et al. Molecular determinants of vanilloid sensitivity in TRPV1. J Biol Chem 2004; 279: 20283-95.

[101] Hui K, Liu B, Qin F. Capsaicin activation of the pain receptor, VR1: multiple open states from both partial and full binding. Biophys J 2003; 84: 2957-68. 
[102] Acs G, Blumberg PM. Comparison of [3H]resiniferatoxin binding to spinal cord and dorsal root ganglia of newborn and adult rats. Life Sci 1994; 54: 1875-82.

[103] Jordt SE, Julius D. Molecular basis for species-specific sensitivity to "hot" chili peppers. Cell 2002; 108: 421-30.

[104] Garcia-Sanz N, Valente P, Gomis A, et al. A role of the transient receptor potential domain of vanilloid receptor I in channel gating. J Neurosci 2007; 27: 11641-50.

[105] Valente P, Garcia-Sanz N, Gomis A, et al. Identification of molecular determinants of channel gating in the transient receptor potential box of vanilloid receptor I. FASEB J 2008; 22: 3298-309.

[106] Welch JM, Simon SA, Reinhart PH. The activation mechanism of rat vanilloid receptor 1 by capsaicin involves the pore domain and differs from the activation by either acid or heat. Proc Natl Acad Sci USA 2000; 97: 13889-94.

[107] Myers BR, Bohlen CJ, Julius D. A yeast genetic screen reveals a critical role for the pore helix domain in TRP channel gating. Neuron 2008; 58: 362-73.

[108] Kuzhikandathil EV, Wang H, Szabo T, et al. Functional analysis of capsaicin receptor (vanilloid receptor subtype 1) multimerization and agonist responsiveness using a dominant negative mutation. J Neurosci 2001; 21: 8697-706.

[109] Jung J, Lee SY, Hwang SW, et al. Agonist recognition sites in the cytosolic tails of vanilloid receptor 1 . J Biol Chem 2002; 277 : 44448-54.

[110] Jordt SE, Tominaga M, Julius D. Acid potentiation of the capsaicin receptor determined by a key extracellular site. Proc Natl Acad Sci USA 2000; 97: 8134-9.

[111] Ryu S, Liu B, Yao J, Fu Q, Qin F. Uncoupling proton activation of vanilloid receptor TRPV1. J Neurosci 2007; 27: 12797-807.

[112] Grandl J, Hu H, Bandell M, et al. Pore region of TRPV3 ion channel is specifically required for heat activation. Nat Neurosci 2008; 11: $1007-13$.

[113] Gavva NR, Tamir R, Klionsky L, et al. Proton activation does not alter antagonist interaction with the capsaicin-binding pocket of TRPV1. Mol Pharmacol 2005; 68: 1524-33.

[114] Roberts LA, Connor M. TRPV1 antagonists as a potential treatment for hyperalgesia. Recent Pat CNS Drug Discov 2006; 1: 6576.

[115] St Pierre M, Reeh PW, Zimmermann K. Differential effects of TRPV channel block on polymodal activation of rat cutaneous nociceptors in vitro. Exp Brain Res 2009; 196: 31-44.

[116] Ryu S, Liu B, Qin F. Low pH potentiates both capsaicin binding and channel gating of VR1 receptors. J Gen Physiol 2003; 122: 4561.

[117] Bezanilla F. How membrane proteins sense voltage. Nat Rev 2008; 9: 323-32.

[118] Roux B. Dissecting the coupling between the voltage sensor and pore domains. Neuron 2006; 52: 568-9.

[119] Borjesson SI, Elinder F. Structure, function, and modification of the voltage sensor in voltage-gated ion channels. Cell Biochem Biophys 2008; 52: 149-74.

[120] Bezanilla F. The voltage sensor in voltage-dependent ion channels. Physiol Rev 2000; 80: 555-92.

[121] Tombola F, Pathak MM, Isacoff EY. How does voltage open an ion channel? Ann Rev Cell Dev Biol 2006; 22: 23-52.

[122] Lu Z, Klem AM, Ramu Y. Coupling between voltage sensors and activation gate in voltage-gated $\mathrm{K}^{+}$channels. J Gen Physiol 2002; 120: 663-76.

[123] Long SB, Campbell EB, Mackinnon R. Voltage sensor of Kv1.2: structural basis of electromechanical coupling. Science 2005; 309: 903-8.

[124] Caprini M, Fava M, Valente P, et al. Molecular compatibility of the channel gate and the $\mathrm{N}$ terminus of S5 segment for voltage-gated channel activity. J Biol Chem 2005; 280: 18253-64.

[125] Lee SY, Banerjee A, MacKinnon R. Two separate interfaces between the voltage sensor and pore are required for the function of voltage-dependent $\mathrm{K}(+)$ channels. PLoS Biol 2009; 7: e47.

[126] Labro AJ, Raes AL, Grottesi A, et al. Kv channel gating requires a compatible S4-S5 linker and bottom part of S6, constrained by noninteracting residues. J Gen Physiol 2008; 132: 667-80.

[127] Islas LD, Sigworth FJ. Electrostatics and the gating pore of Shaker potassium channels. J Gen Physiol 2001; 117: 69-89.

[128] Jogini V, Roux B. Dynamics of the Kv1.2 voltage-gated K+ channel in a membrane environment. Biophys J 2007; 93: 3070-82.
[129] Asamoah OK, Wuskell JP, Loew LM, Bezanilla F. A fluorometric approach to local electric field measurements in a voltage-gated ion channel. Neuron 2003; 37: 85-97.

[130] Chanda B, Asamoah OK, Blunck R, Roux B, Bezanilla F. Gating charge displacement in voltage-gated ion channels involves limited transmembrane movement. Nature 2005; 436: 852-6.

[131] Nilius B, Talavera K, Owsianik G, et al. Gating of TRP channels: a voltage connection? J Physiol 2005; 567: 35-44.

[132] Voets T, Owsianik G, Janssens A, Talavera K, Nilius B. TRPM8 voltage sensor mutants reveal a mechanism for integrating thermal and chemical stimuli. Nat Chem Biol 2007; 3: 174-82.

[133] Oseguera AJ, Islas LD, Garcia-Villegas R, Rosenbaum T. On the mechanism of TBA block of the TRPV1 channel. Biophy J 2007; 92: 3901-14

[134] Matta JA, Ahern GP. Voltage is a partial activator of thermosensitive TRP channels. J Physiol 2007; 585(pt 2): 469-82.

[135] Brauchi S, Orta G, Salazar M, Rosenmann E, Latorre R. A hotsensing cold receptor: C-terminal domain determines thermosensation in transient receptor potential channels. J Neurosci 2006; 26: 4835-40.

[136] Cole KS, Moore JW. Potassium ion current in the squid giant axon: dynamic characteristic. Biophys J 1960; 1: 1-14

[137] Brauchi S, Orio P, Latorre R. Clues to understanding cold sensation: thermodynamics and electrophysiological analysis of the cold receptor TRPM8. Proc Natl Acad Sci USA 2004; 101: 15494-9.

[138] Horrigan FT, Aldrich RW. Allosteric voltage gating of potassium channels II. Mslo channel gating charge movement in the absence of $\mathrm{Ca}\left(2^{+}\right)$. J Gen Physiol 1999; 114: 305-36.

[139] Horrigan FT, Cui J, Aldrich RW. Allosteric voltage gating of potassium channels I. Mslo ionic currents in the absence of $\mathrm{Ca}\left(2^{+}\right)$. J Gen Physiol 1999; 114: 277-304.

[140] Horrigan FT, Aldrich RW. Coupling between voltage sensor activation, $\mathrm{Ca}^{2+}$ binding and channel opening in large conductance (BK) potassium channels. J Gen Physiol 2002; 120: 267-305.

[141] Liu B, Hui K, Qin F. Thermodynamics of heat activation of single capsaicin ion channels VR1. Biophys J 2003; 85: 2988-3006.

[142] Sedgwick S, Smerdon S. The ankyrin repeat: a diversity of interactions on a common structural framework. Trends Biochem Sci 1999; 24: 311-6.

[143] Owsianik G, D'hoedt D, Voets T, Nilius B. Structure-function relationship of the TRP channel superfamily. Rev Physiol Biochem Pharmacol 2006; 156: 61-90.

[144] Gaudet R. A primer on ankyrin repeat function in Trp channels and beyond. Mol BioSyst 2008; 4: 372-9.

[145] Hoenderop JGJ, Voets T, Hoefs S, et al. Homo- and heterotetrameric architecture of the epitelial $\mathrm{Ca}^{2+}$ channels TRPV5 and TRPV6. EMBO J 2003; 22: 776-85.

[146] Hellwig N, Albrecht N, Harteneck C, Schultz G, Schaefer M. Homo- and heteromeric assembly of TRPV channel subunits. J Cell Sci 2004; 118: 917-28

[147] García-Sanz N, Fernández-Carvajal A, Morenilla-Palao C, et al. Identification of a tetramerization domain in the $\mathrm{C}$ terminus of the Vanilloid receptor. J Neurosci 2004; 24: 5307-14.

[148] Chang Q, Gyftogianni E, van de Graaf SF, et al. Molecular determinants in TRPV5 channel assembly. J Biol Chem 2004; 279 : 54304-11.

[149] Erler I, Hirnet D, Wissenbach U, Flockerzi V, Niemeyer B. $\mathrm{Ca}^{2+}$ selective transient receptor potential $\mathrm{V}$ channel architecture and function require a specific ankyrin repeat. J Biol Chem 2004; 279 : 34456-63.

[150] Arniges M, Fernández-Fernandez J, Albrecht N, Schaefer M, Valverde M. Human TRPV4 channel splice variants revealed a key role of ankyrin domain in multimerization and trafficking. $\mathrm{J}$ Biol Chem 2006; 281: 1580-6.

[151] Zerangue N, Jan YN, Jan LY. An artificial tetramerization domain restores efficient assembly of functional Shaker channels lacking T1. Proc Natl Acad Sci USA 2000; 97: 3591-5.

[152] Jenke M, Sanchez A, Monje F, et al. C-terminal domains implicated in the functional surface expression of potassium channels. EMBO J 2003; 22: 395-403.

[153] Quirk JC, Reinhart PH. Identification of a novel tetramerization domain in large conductance K(ca) channels. Neuron 2001; 32: 13 23.

[154] Lishko P, Procko E, Jin X, Phelps CB, Gaudet R. The ankyrin repeats of TRPV1 bind multiple ligands and modulate channel sensitivity. Neuron 2007; 54: 905-18. 
[155] Rosenbaum T, Gordon-Shaag A, Munari M, Gordon SE. $\mathrm{Ca}^{2+} /$ calmodulin modulates TRPV1 activation by capsaicin. J Gen Physiol 2004; 123: 53-62.

[156] Hinman A, Chuang HH, Bautista DM, Julius D. TRP channel activation by reversible covalent modification. Proc Natl Acad Sci USA 2006; 103: 19564-8.

[157] Corey D, García-Añoveros J, Holt J, et al. TRPA1 is a candidate for the mechanosensitive transduction channel of vertebrate hair cells. Nature 2004; 432: 723-30.

[158] Birder LA, Nakamura Y, Kiss S, et al. Altered urinary bladder function in mice lacking the vanilloid receptor TRPV1. Nat Neurosci 2002; 5: 856-60.

[159] Brider L, Kanai A, Groat Wd, et al. Vanilloid receptor expression suggests a sensory role for urinary bladder epithelial cells. Proc Natl Acad Sci USA 2001; 98: 13396-401.

[160] Howard J, Bechstedt S. Hypothesis: A helix of ankyrin repeats of the NOMPC-TRP ion channel si the gating spring of mechanoreceptors. Curr Biol 2004; 14: R224-6.

[161] Naeini R, Witty M, Séguéla P, Bourque C. An N-terminal variant of TRPV1 channel is required for osmosensory transduction. Nat Neurosci 2005; 9: 93-8.

[162] Ciura S, Bourque C. Transient receptor potential vanilloid 1 is required for intrinsic osmoreception in organum vasculosum lamina terminalis neurons and for normal thirst responses to systemic hyperosmolality. J Neurosci 2006; 26: 9069-75.

[163] Liu L, Chen L, Liedtke W, Simon S. Changes in osmolality sensitize the response to capsaicin in trigeminal sensory neurons. J Neurophysiol 2007; 97: 2001-15.

[164] Prescott ED, Julius D. A modular PIP2 binding site as a determinant of capsaicin receptor sensitivity. Science 2003; 300: 1284-88.

[165] Stein AT, Ufret-Vincenty CA, Hua L, Santana LF, Gordon SE. Phosphoinositide 3-kinase binds to TRPV1 and mediates NGFstimulated TRPV1 trafficking to the plasma membrane. J Gen Physiol 2006; 128: 509-22.

[166] Klein R, Ufret-Vincenty C, Hua L, Gordon S. Determinants of molecular specificity in phosphoinositide regulation. J Biol Chem 2008; 283: 26208-16.

[167] Lukacs V, Thyagarajan B, Varnai P, et al. Dual regulation of TRPV1 by phosphoinositides. J Neurosci 2007; 27: 7070-80.

[168] MacKinnon R. Potassium channels. FEBS Lett 2003; 555: 62-5.

[169] Webster SM, Del Camino D, Dekker JP, Yellen G. Intracellular gate opening in Shaker $\mathrm{K}+$ channels defined by high-affinity metal bridges. Nature 2004; 428: 864-8.

[170] del Camino D, Yellen G. Tight steric closure at the intracellular activation gate of a voltage-gated $\mathrm{K}(+)$ channel. Neuron 2001; 32: 649-56.

[171] Ding S, Ingleby L, Ahern CA, Horn R. Investigating the putative glycine hinge in Shaker potassium channel. J Gen Physiol 2005; 126: 213-26.

[172] Yellen G, Sodickson D, Chen TY, Jurman ME. An engineered cysteine in the external mouth of a $\mathrm{K}^{+}$channel allows inactivation to be modulated by metal binding. Biophys J 1994; 66: 1068-75.

[173] Gomez-Lagunas F. $\mathrm{Na}(+)$ interaction with the pore of Shaker B $\mathrm{K}(+)$ channels: zero and low $\mathrm{K}(+)$ conditions. J Gen Physiol 2001; 118: 639-48.

[174] Contreras JE, Srikumar D, Holmgren M. Gating at the selectivity filter in cyclic nucleotide-gated channels. Proc Natl Acad Sci USA 2008; 105: 3310-4.

[175] Flynn GE, Zagotta WN. Conformational changes in S6 coupled to the opening of cyclic nucleotide-gated channels. Neuron 2001; 30: 689-98.

[176] Flynn GE, Zagotta WN. A cysteine scan of the inner vestibule of cyclic nucleotide-gated channels reveals architecture and rearrangement of the pore. J Gen Physiol 2003; 121: 563-82.

[177] Heginbotham L, Lu Z, Abramson T, MacKinnon R. Mutations in the K+ channel signature sequence. Biophys J 1994; 66: 1061-7.

[178] Ferrer-Montiel A, Garcia-Martinez C, Morenilla-Palao C, et al. Molecular architecture of the vanilloid receptor. Insights for drug design. Eur J Biochem 2004; 271: 1820-6.

[179] Liu B, Yao J, Wang Y, Li H, Qin F. Proton inhibition of unitary currents of vanilloid receptors. J Gen Physiol 2009; 134: 243-58.

[180] Jean K, Bernatchez G, Klein H, et al. Role of aspartate residues in $\mathrm{Ca}(2+)$ affinity and permeation of the distal $\mathrm{ECaC} 1$. Am J Physiol Cell Physiol 2002; 282: C665-72.
[181] Voets T, Janssens A, Droogmans G, Nilius B. Outer pore architecture of a $\mathrm{Ca}^{2}+$-selective TRP channel. J Biol Chem 2004; 279: 15223-30.

[182] Nilius B, Prenen J, Janssens A, et al. The selectivity filter of the cation channel TRPM4. J Biol Chem 2005; 280: 22899-906.

[183] Dodier Y, Dionne F, Raybaud A, Sauve R, Parent L. Topology of the selectivity filter of a TRPV channel: rapid accessibility of contiguous residues from the external medium. Am J Physiol Cell Physiol 2007; 293: C1962-70.

[184] Dodier Y, Banderali U, Klein H, et al. Outer pore topology of the ECaC-TRPV 5 channel by cysteine scan mutagenesis. J Biol Chem 2004; 279: 6853-62.

[185] Khakh BS, Bao XR, Labarca C, Lester HA. Neuronal P2X transmitter-gated cation channels change their ion selectivity in seconds. Nat Neurosci 1999; 2: 322-30.

[186] Virginio C, MacKenzie A, Rassendren FA, North RA, Surprenant A. Pore dilation of neuronal P2X receptor channels. Nat Neurosci 1999; 2: 315-21.

[187] Chung MK, Guler AD, Caterina MJ. TRPV1 shows dynamic ionic selectivity during agonist stimulation. Nat Neurosci 2008; 11: 55564.

[188] Ahern GP, Brooks IM, Miyares RL, Wang XB. Extracellular cations sensitize and gate capsaicin receptor TRPV1 modulating pain signaling. J Neurosci 2005; 25: 5109-16.

[189] Tousova K, Vyklicky L, Susankova K, Benedikt J, Vlachova V. Gadolinium activates and sensitizes the vanilloid receptor TRPV1 through the external protonation sites. Mol Cell Neurosci 2005; 30: 207-17.

[190] Ahern GP, Wang X, Miyares RL. Polyamines are potent ligands for the capsaicin receptor TRPV1. J Biol Chem 2006; 281: 8991-5.

[191] Baumann TK, Martenson ME. Extracellular protons both increase the activity and reduce the conductance of capsaicin- gated channels. J Neurosci 2000; 20: RC80.

[192] Samways DS, Khakh BS, Egan TM. Tunable calcium current through TRPV1 receptor channels. J Biol Chem 2008; 283: 31274 8.

[193] Yeh BI, Kim YK, Jabbar W, Huang CL. Conformational changes of pore helix coupled to gating of TRPV5 by protons. EMBO J 2005; $24: 3224-34$.

[194] Armstrong CM. Interaction of tetraethylammonium ion derivatives with the potassium channels of giant axons. J Gen Physiol 1971; 58: 413-37.

[195] Armstrong CM, Hille B. The inner quaternary ammonium ion receptor in potassium channels of the node of Ranvier. J Gen Physiol 1972; 59: 388-400.

[196] Bezanilla F, Armstrong CM. Negative conductance caused by entry of sodium and cesium ions into the potassium channels of squid axons. J Gen Physiol 1972; 60: 588-608.

[197] Jara-Oseguera A, Llorente I, Rosenbaum T, Islas LD. Properties of the inner pore region of TRPV1 channels revealed by block with quaternary ammoniums. J Gen Physiol 2008; 132: 547-62.

[198] Susankova K, Ettrich R, Vyklicky L, Teisinger J, Vlachova V. Contribution of the putative inner-pore region to the gating of the transient receptor potential vanilloid subtype 1 channel (TRPV1). J Neurosci 2007; 27: 7578-85.

[199] Cornette JL, Cease KB, Margalit H, et al. Hydrophobicity scales and computational techniques for detecting amphipathic structures in proteins. J Mol Biol 1987; 195: 659-85.

[200] Li-Smerin Y, Swartz KJ. Helical structure of the $\mathrm{COOH}$ terminus of S3 and its contribution to the gating modifier toxin receptor in voltage-gated ion channels. J Gen Physiol 2001; 117: 205-18.

[201] Mohapatra DP, Wang SY, Wang GK, Nau C. A tyrosine residue in TM6 of the Vanilloid Receptor TRPV1 involved in desensitization and calcium permeability of capsaicin-activated currents. Mol Cell Neurosci 2003; 23: 314-24.

[202] Birnbaumer L, Yildirim E, Abramowitz J. A comparison of the genes coding for canonical TRP channels and their $\mathrm{M}, \mathrm{V}$ and $\mathrm{P}$ relatives. Cell Calcium 2003; 33: 419-32.

[203] Xu H, Tian W, Fu Y, et al. Functional effects of nonsynonymous polymorphisms in the human TRPV1 gene. Am J Physiol Renal Physiol 2007; 296: F1865-76.

[204] Kim H, Neubert J, Miguel AS, et al. Genetic influence on variability in human acute experimental pain sensitivity associated with gender, ethnicity and psychological temperament. Pain 2004; 109: 488-96. 
[205] O'Sullivan SE, Kendall DA, Randall MD. The effects of Delta9tetrahydrocannabinol in rat mesenteric vasculature, and its interactions with the endocannabinoid anandamide. Br J Pharmacol 2005; 145: 514-26.

[206] Dux M, Santha P, Jancso G. Capsaicin-sensitive neurogenic sensory vasodilatation in the dura mater of the rat. J Physiol 2003; 552: 859-67.

[207] Wang Y, Wang DH. Neural control of blood pressure: focusing on capsaicin-sensitive sensory nerves. Cardiovasc Hematol Disord Drug Targets 2007; 7: 37-46.

[208] Tsutsumi S, Tomioka A, Sudo M, et al. Propofol activates vanilloid receptor channels expressed in human embryonic kidney 293 cells. Neurosci Lett 2001; 312: 45-9.

[209] Tan C, Onsiong M. Pain on injection of propofol. Anaesthesia 1998; 53: 468-76.

[210] Picard P, Tramèr M. Prevention of pain on injection with propofol: a quantitative systematic review. Anesth Analg 2000; 90: 963-9.

[211] Doenicke A, Roizen M, Rau J, Kellermann W, Babl J. Reducing pain during propofol injection: the role of the solvent. Anesth Analg 1996; 82: 472-4.

[212] Jara-Oseguera A, Simon S, Rosenbaum T. TRPV1: On the Road to Pain Relief. Curr Mol Pharmacol 2008; 1: 255-69.

[213] Wilson-Gerwing TD, Dmyterko MV, Zochodne DW, Johnston JM, Verge VM. Neurotrophin-3 suppresses thermal hyperalgesia associated with neuropathic pain and attenuates transient receptor potential vanilloid receptor-1 expression in adult sensory neurons. J Neurosci 2005; 25: 758-67.

[214] Amaya F, Oh-hashi K, Naruse Y, et al. Local inflammation increases vanilloid receptor 1 expression within distinct subgroups of DRG neurons. Brain Res 2003; 963: 190-6.

[215] Michael GJ, Priestley JV. Differential expression of the mRNA for the vanilloid receptor subtype 1 in cells of the adult rat dorsal root and nodose ganglia and its downregulation by axotomy. J Neurosci 1999; 19: 1844-54.

[216] Staaf S, Oerther S, Lucas G, Mattsson JP, Ernfors P. Differential regulation of TRP channels in a rat model of neuropathic pain. Pain 2009; 144: 187-99.

[217] Pabbidi RM, Yu SQ, Peng S, et al. Influence of TRPV1 on diabetes-induced alterations in thermal pain sensitivity. Mol Pain 2008; 4: 9 .

[218] Winter J, Forbes CA, Sternberg J, Lindsay RM. Nerve growth factor (NGF) regulates adult rat cultured dorsal root ganglion neuron responses to the excitotoxin capsaicin. Neuron 1988; 1: 973-81.

[219] Anand U, Otto WR, Casula MA, et al. The effect of neurotrophic factors on morphology, TRPV1 expression and capsaicin responses of cultured human DRG sensory neurons. Neurosci Lett 2006; 399 : 51-6.

[220] Miller MS, Buck SH, Sipes IG, Burks TF. Altered axoplasmic transport of nerve growth factor by capsaicin. Proc West Pharmacol Soc 1982; 25: 87-8.

[221] Robinson DR, McNaughton PA, Evans ML, Hicks GA. Characterization of the primary spinal afferent innervation of the mouse colon using retrograde labelling. Neurogastroenterol Motil 2004; 16: 113 24.

[222] Chan CL, Facer P, Davis JB, et al. Sensory fibres expressing capsaicin receptor TRPV1 in patients with rectal hypersensitivity and faecal urgency. Lancet 2003; 361: 385-91.

[223] Matthews PJ, Aziz Q, Facer P, et al. Increased capsaicin receptor TRPV1 nerve fibres in the inflamed human oesophagus. Eur J Gastroenterol Hepatol 2004; 16: 897-902.

[224] Trevisani M, Smart D, Gunthorpe MJ, et al. Ethanol elicits and potentiates nociceptor responses via the vanilloid receptor-1. Nat Neurosci 2002; 5: 546-51.
[225] Vetter I, Wyse BD, Roberts-Thomson SJ, Monteith GR, Cabot PJ. Mechanisms involved in potentiation of transient receptor potential vanilloid 1 responses by ethanol. Eur J Pain 2008; 12: 441-54.

[226] Schicho R, Krueger D, Zeller F, et al. Hydrogen sulfide is a novel prosecretory neuromodulator in the Guinea-pig and human colon. Gastroenterology 2006; 131: 1542-52.

[227] Xu GY, Winston JH, Shenoy M, et al. The endogenous hydrogen sulfide producing enzyme cystathionine-beta synthase contributes to visceral hypersensitivity in a rat model of irritable bowel syndrome. Mol Pain 2009; 5: 44.

[228] Adcock JJ. TRPV1 receptors in sensitisation of cough and pain reflexes. Pulm Pharmacol Ther 2009; 22: 65-70.

[229] McLeod RL, Correll CC, Jia Y, Anthes JC. TRPV1 antagonists as potential antitussive agents. Lung 2008; 186 (Suppl 1): S59-65.

[230] Jia Y, Lee LY. Role of TRPV receptors in respiratory diseases. Biochim Biophys Acta 2007; 1772: 915-27.

[231] Kollarik M, Brozmanova M. Cough and gastroesophageal reflux: insights from animal models. Pulm Pharmacol Ther 2009; 22: 1304.

[232] Kollarik M, Ru F, Undem BJ. Acid-sensitive vagal sensory pathways and cough. Pulm Pharmacol Ther 2007; 20: 402-11.

[233] Chen Y, Geis C, Sommer C. Activation of TRPV1 contributes to morphine tolerance: involvement of the mitogen-activated protein kinase signaling pathway. J Neurosci 2008; 28: 5836-45.

[234] Sjogren P, Jonsson T, Jensen NH, Drenck NE, Jensen TS. Hyperalgesia and myoclonus in terminal cancer patients treated with continuous intravenous morphine. Pain 1993; 55: 93-7.

[235] Mao J, Price DD, Mayer DJ. Mechanisms of hyperalgesia and morphine tolerance: a current view of their possible interactions. Pain 1995; 62: 259-74.

[236] Mao J, Sung B, Ji RR, Lim G. Chronic morphine induces downregulation of spinal glutamate transporters: implications in morphine tolerance and abnormal pain sensitivity. J Neurosci 2002; 22: 8312-23.

[237] Vanderah TW, Suenaga NM, Ossipov MH, et al. Tonic descending facilitation from the rostral ventromedial medulla mediates opioidinduced abnormal pain and antinociceptive tolerance. J Neurosci $2001 ; 21: 279-86$.

[238] Vetter I, Wyse BD, Monteith GR, Roberts-Thomson SJ, Cabot PJ. The mu opioid agonist morphine modulates potentiation of capsaicin-evoked TRPV1 responses through a cyclic AMP-dependent protein kinase A pathway. Mol Pain 2006; 2: 22.

[239] Vetter I, Cheng W, Peiris M, et al. Rapid, opioid-sensitive mechanisms involved in transient receptor potential vanilloid 1 sensitization. J Biol Chem 2008; 283: 19540-50.

[240] Alessandri-Haber N, Dina OA, Yeh JJ, et al. Transient receptor potential vanilloid 4 is essential in chemotherapy-induced neuropathic pain in the rat. J Neurosci 2004; 24: 4444-52.

[241] Alessandri-Haber N, Dina OA, Joseph EK, Reichling DB, Levine JD. Interaction of transient receptor potential vanilloid 4, integrin, and SRC tyrosine kinase in mechanical hyperalgesia. J Neurosci 2008; 28: 1046-57.

[242] Frederick J, Buck ME, Matson DJ, Cortright DN. Increased TRPA1, TRPM8, and TRPV2 expression in dorsal root ganglia by nerve injury. Biochem Biophys Res Commun 2007; 358: 1058-64.

[243] Alvarado LT, Perry GM, Hargreaves KM, Henry MA. TRPM8 Axonal expression is decreased in painful human teeth with irreversible pulpitis and cold hyperalgesia. J Endod 2007; 33: 1167-71.

[244] Namer B, Kleggetveit IP, Handwerker H, Schmelz M, Jorum E. Role of TRPM8 and TRPA1 for cold allodynia in patients with cold injury. Pain 2008; 139: 63-72. 